\title{
CIBERLITERATURA Y CIBERCULTURA EN EL ÁMBITO HISPÁNICO
}

\section{CYBERLITERATURE AND CYBERCULTURE IN LATIN AMERICA AND SPAIN}

Bernat CASTANY PRADO

Universidad de Barcelona bcastany@ub.edu

Resumen: El objetivo de este trabajo es realizar una panorámica de los cambios que la escritura y la lectura de obras literarias han experimentado en las últimas dos décadas a raíz de la generalización de los soportes digitales, la conexión a internet y la realidad virtual. La primera parte del trabajo se centra en los cambios que han tenido lugar en el ámbito de la escritura literaria, para lo cual se sigue una tipología genérica clásica, que distinguirá entre cibernarrativa, ciberensayo, ciberpoesía y ciberteatro. La segunda parte se ocupa de las modificaciones de los hábitos de lectura de obras literarias, distinguiendo entre el ámbito del libro electrónico o ebook no conectado y el ámbito de la lectura en red o ciberlectura. En las conclusiones se exponen las principales valoraciones -positivas y negativas- que suelen circular acerca de la nueva cultura digital.

Palabras clave: Ciberliteratura; Cibercultura; Literatura y tecnología; Literatura española e hispanoamericana.

Abstract: The aim of this work is to make an overview of the changes that the writing and reading of literary works have experienced in the last two decades as a result of the generalization of digital media, the Internet connection and virtual reality. The first part of the work focuses on the changes that have taken place in the field of literary writing, for which a classic generic typology is followed, which will distinguish between cybercrime, cyber-essay, cyber poetry and cyber art. The second part deals with the changes in the reading habits of literary works, distinguishing between the scope of the electronic book or unconnected ebook and the field of reading on the web or cyber reading. The conclusions show the main assessments - positive and negative - that tend to circulate about the new digital culture.

Keywords: Cyberliterature; Cyberculture; Literature and technology; Spanish and Latin American literature. 


\section{1}

\section{Introducción}

La cuestión de la escritura y la lectura en la época digital se ha convertido en una verdadera obsesión, tanto para los académicos como para los editores, docentes, escritores, lectores y usuarios, en general. Como cualquier otra innovación técnica, desde Copérnico o Galileo -si no desde la domesticación misma del fuego-, el mundo digital ha suscitado a la vez esperanzas utópicas y ansiedades apocalípticas, que valoraremos en la última parte de este informe. Con todo, avancemos que este interés apasionado implica dos dificultades mayores a la hora de realizar un estado de la cuestión sobre el tema.

En primer lugar, la ingente cantidad de escritos -no sólo en el ámbito de las lenguas española, inglesa, francesa, italiana o alemana, sino también en el de otras que nos son en gran medida inaccesibles- y la enorme variedad de formatos -libros, artículos académicos, estudios, entrevistas, blogs- hacen prácticamente imposible leer una parte representativa de la bibliografía existente sobre este tema. En segundo lugar, el posicionamiento apriorístico, tanto ideológico como sentimental, de aquellos que han pensado sobre esta cuestión nos obliga a ser circunspectos a la hora de leer, no sólo los escritos de un político o un bloguero, sino también una monografía académica o un experimento sociológico sobre hábitos de lectura.

Para enfrentarnos al primer problema, de corte cuantitativo, debemos combinar dos estrategias. De un lado, existen estudios generales sobre la literatura digital, que pueden proporcionarnos una primera visión panorámica. Tal sería el caso, en lengua española, de los volúmenes colectivos $L a$ literatura en la era electrónica (2006) y Nuevos géneros discursivos: los textos electrónicos (2003), así como de El libro digital y la WWW (2000), de Lluis Codina. En lenguas extranjeras nos encontramos con obras clásicas como Hypermedia and Literary Studies (1991) o Hypertext 3.0 (2006), de George Landow; Texte et ordinateur (1998), de Jacques Anis; Hamlet en la holocubierta: El futuro de la narrativa en el ciberespacio (1999), de Janet Murray; Reading Network Fiction (2007), de David Ciccoricco; o los volúmenes colectivos Beyond the Screen. Trasnformations of Literary Structures, Interfaces and Genres (2010) o Reading Moving Letters. Digital Literature in Research and Teaching: A Handbook (2010). También existen excelentes estudios panorámicos que se centran en el estado de la literatura digital en el ámbito hispánico. Pueden consultarse al respecto, los volúmenes colectivos Mutantes. Narrativa española de última generación (2007) y Escrituras digitales (2008), así como «La literatura digital en español» (2011: 38-66), de Dolores Romero López o Escrituras para el siglo XXI. Literatura y blogosfera (2014), de Daniel Escandell.

Por supuesto, también existe una abundante bibliografía sobre múltiples aspectos particulares relacionados con la revolución digital, como, por ejemplo, el hipertexto (Landow, 2006; Lamarca Lapuente, 2005), la realidad virtual (Casey, 1994; Cadoz, 1995; López-Pelliza, 2015), la mutación de los modos tradicionales de narrar (Rodríguez Ruiz, 2006, Escandell, 2014), la inteligencia artificial (Barceló García, 2005), la idea de simulacro (Talens, 1995; Baudrillard, 2001) o los nuevos hábitos de 
lectura (Mangen, 2013 y 2014). Será, sin embargo, en cada uno de los apartados de este estudio, donde ofreceremos una bibliografía selecta algo más detallada sobre todos estos temas. Queda claro, en todo caso, el carácter inabarcable de la bibliografía acerca de este tema.

La segunda estrategia que debe añadirse a la lectura de obras panorámicas es la lectura dispersa, variada y azarosa, al modo de las fishing expeditions o «expediciones de pesca» científicas, que es el nombre que se le da, en el ámbito de las ciencias, a un tipo de experimentos de corte tentativo en el que, sin establecerse a priori un objetivo claro, se recoge al azar una gran cantidad de información, con la esperanza de hallar algún tipo de hecho o evidencia. Esta segunda estrategia va a ser cada vez más usada, y debería ser tematizada y sistematizada, debido a la cantidad inabarcable de información sobre cualquier tema a la que hoy podemos acceder sin apenas salir de casa. Por así decirlo, antes el azar seleccionaba nuestras lecturas bajo la forma de la accesibilidad o inaccesibilidad de las fuentes. Hoy, en cambio, éstas nos resultan globalmente más accesibles, y por eso mismo somos nosotros quienes debemos operar ese azar, navegando y seleccionando sin un criterio perfecto.

En lo que respecta al segundo problema, de corte cualitativo e ideológico, todo acercamiento bibliográfico a un tema que despierta tantos entusiasmos y susceptibilidades debe ser muy cuidadoso, tanto en lo que respecta a los escritos con una fuerte carga ideológica, como en lo que respecta a los escritos periodísticos o académicos, que no siempre gozan de la neutralidad que podría esperarse de ellos. Así, para estar sobre aviso de las distorsiones ideológicas o sentimentales que pueden sufrir los textos a los que acudamos, sería bueno realizar un análisis de las diferentes actitudes y mitos que el mundo de la tecnología suele despertar. Ése será, precisamente, el objeto de la última parte de este informe.

\section{Ciberescritura}

Todavía no existe consenso acerca de cómo llamar a la literatura creada o leída en un soporte digital, normalmente conectado. El uso vacila entre términos como «literatura electrónica», «literatura digital», «hiperliteratura» $\mathrm{y}$ «ciberliteratura». Cada uno de estos términos capta algún aspecto importante de este nuevo tipo de realidad literaria, si bien ninguno logra captarlos todos, ya sea porque se acuñó en una época en la que varios de esos aspectos no existían más que en potencia -la conectividad o la realidad virtual, por ejemplo, todavía estaban en ciernes en los años ochenta y noventa-, ya sea porque los diversos tipos de prácticas existentes tienden a enfatizar más unos aspectos que otros: lo hipertextual, lo hipermediático o la creación colectiva.

Los términos «literatura electrónica»o «literatura digital», por ejemplo, captan bien la importancia de los nuevos soportes, si bien no se refieren directamente a un hecho tan importante como es la conexión a internet, ni expresan cómo este tipo de literatura va más allá del mero soporte, ya que un ebook no es, propiamente hablando, literatura digital, sino una mera reproducción digital de una obra literaria. Por su parte, el término «hiperliteratura» capta bien el carácter hipertextual de este tipo de obras, si bien no da cuenta de otros aspectos importantes como, por ejemplo, el uso de las redes 
sociales o la coparticipación de los lectores. Quizás el término «ciberliteratura» sea uno de los más acertados, ya que recoge uno de los elementos fundamentales de este tipo de literatura, como es el hecho de la navegación y de la lectura salteada y activa -recordemos que el término «cibernética», del que deriva, hace referencia a la palabra griega kybernêtikê, que Platón utilizó para referirse a la técnica de conducción de una nave- ${ }^{1}$, lo cual, a su vez, incluye la idea de soporte digital, hipertextualidad y participación activa.

Independientemente del término que prefiramos utilizar, coincidimos con Juan José Díez, director del portal Literatura electrónica hispánica, albergado en la Biblioteca Cervantes Vitual, en que los tres rasgos fundamentales que distinguen la ciberliteratura de la literatura convencional son el hipertexto, los recursos multimedia y la interactividad. Insistamos de nuevo, pues, en que no debe confundirse la ciberliteratura con los libros tradicionales digitalizados que pueden leerse en dispositivos de tinta electrónica, conocidos como «e-book»o «libro electrónico» (2009: html)².

La ciberliteratura habría nacido, en 1987, con la novela hipertextual Afternoon, a story, de Michael Joyce, en la que cada palabra es un enlace que lleva a alguna otra parte de la novela, incluidos los meros nexos gramaticales, que llevan siempre a una misma frase, que recuerda el vago argumento de la misma: «Quiero decir que quizás he visto morir a mi hijo esta mañana». Aunque la ciberliteratura no llegará al mundo hispánico hasta diez años más tarde, hoy en día es un ámbito fértil tanto en España como en toda Hispanoamérica ${ }^{3}$.

Los principales repositorios de literatura digital en el ámbito hispánico, y algunas de las fuentes principales de este estudio, son la Biblioteca Digital del Grupo de investigación Literatura Españolas y Europeas del Texto al Hipertexto (https://www.ucm.es/leethi/que), la Biblioteca de literatura digital (http://repositorios.fdi.ucm.es/CIBERIA) y el portal Literatura electrónica hispánica, incluido en Biblioteca Cervantes Virtual, de la Universidad de Alicante (http://www.cervantesvirtual.com/bib/ portal/literaturaelectronica/).

A la hora de aventurar una tipología, debemos tener en cuenta que la ciberliteratura es un fenómeno reciente y proteico, lo cual dificulta mucho su sistematización. Existen numerosas tipologías posibles, según se atienda, por ejemplo, a los procesos de creación (hipertexto, hipermedia, escritura colaborativa, redes sociales) o al género literario (narrativa, teatro, poesía, no ficción). En este informe trataremos de fusionar ambas tipologías, realizando, en primer lugar, una tipología de tipo genérica, que distinguirá entre cibernarrativa, ciberensayo, ciberpoesía y ciberteatro, para, a continuación,

\footnotetext{
${ }^{1}$ En 1948, Norbert Wiener recuperó dicho término en Cibernética o el control y comunicación en animales y máquinas, y de ahí pasó a designar, como indica el Diccionario de la Real Academia «el estudio de las analogías entre los sistemas de control y comunicación de los seres vivos y los de las máquinas», y luego, simplemente, todo aquello «creado y regulado mediante computadora»y, más específicamente, aquello «perteneciente o relativo a la realidad virtual» (véase al respecto, López-Pellisa, 2015: 44).

${ }^{2}$ Pueden hallarse interesantes consideraciones sobre esta cuestión en Escandell (2014: 14-17).

${ }^{3}$ Cabe señalar que el martes 29 de marzo de 2016, Google dedicó uno de sus doodles a la española Ángela Ruiz Robles, por considerar su «enciclopedia mecánica», de 1949, precursora del ebook. Véase al respecto «Ángela Ruiz Robles: Google rinde homenaje a la precursora del 'eBook'», El País, 29 de marzo de 2016; en http://cultura.elpais.com/cultura/2016/03/ 28/actualidad/1459145834_002175.html (última consulta, 7-10-2018).
} 
distinguir, dentro de cada uno de estos apartados, entre los diferentes modos de producción de los textos.

\section{1. Cibernarrativa:}

Los términos «cibernarrativa»o «narrativa hipertextual» designan un tipo de obra narrativa que trasciende la escritura y la lectura lineal, en virtud de una serie de enlaces o links que permiten saltar a otras partes del texto e, incluso, a otras partes externas al texto, como sería el caso de webs, blogs o entradas de enciclopedia. Aunque en sus inicios, este tipo de literatura existía sin conexión a internet, hoy en día lo más habitual es que esté conectada, ya que muchas de las partes externas al texto suelen estar disponibles en red.

Se ha hablado mucho acerca de los antecedentes de la narrativa hipertextual. Rayuela (1963), de Julio Cortázar, con sus diversos modos de lectura, ha sido vista como un «hipertexto anticipado» (Alayón Gómez, 2009: html). También puede verse un elemento hipertextual en ciertos libros sagrados, como la Biblia o el I Ching, que aceptan y estimulan este tipo de lecturas salteadas, mediante referencias cruzadas a otros versículos o pasajes del mismo texto; obras grecolatinas clásicas, que aceptan también una lectura azarosa y fragmentaria, como la que propugnaba la ars virgiliana; obras enciclopédicas, como el Diccionario histórico y crítico de Pierre Bayle (1695-1697), que contenía largas notas al pie, que incluían, a su vez, largas notas a pie, que contenían otras notas al pie; o la Enciclopedia francesa (1751-1772), que utilizó el sistema de llamadas entre entradas para introducir nuevos niveles de significado. Existieron también métodos vanguardistas o experimentales como, por ejemplo, el «cadáver exquisito» de los surrealistas o la literatura combinatoria del Ouvrier de Litérature Potentielle (Oulipo), que prefiguran, de algún modo, algunas prácticas hipertextuales o colaborativas.

Sin embargo, existe consenso en considerar que la narrativa hipertextual está estrechamente ligada con los sistemas de creación, almacenamiento y compartición informáticos. Por esta razón, la primera formulación contemporánea del hipertexto se atribuye a Vannevar Bush, quien, en su artículo «As we may think» (1945), consideró que ése sería el modo de escritura y de lectura característica del Memex, una base de datos y de documentos que nunca pasó de ser un mero proyecto, pero que ya anunciaba la futura existencia de internet.

En 1965, Ted Nelson acuñará el término «hipertexto». Con todo, no será hasta 1967, cuando Andries van Dam cree el primer sistema de edición hipertextual, o Hypertext Editing System (HES). Así, pues, la narrativa hipertextual «es un sistema informático de producción, manipulación y almacenaje de información textual, que enlaza campos de significación por medio de nodos o hiperenlaces, de una manera no lineal, interactiva y plural» (Alayón Gómez, 2009: html) ${ }^{4}$.

\footnotetext{
${ }^{4}$ Puede encontrarse una excelente exposición de los antecedentes e historia del mundo digital en el apartado «Genealogía de la realidad virtual», incluido en Patologías de la realidad virtual, de Teresa López-Pellisa (2015: 27-67).
} 
Dentro de la narrativa hipertextual podemos establecer dos tipologías básicas. De un lado, podemos atender a los modos de creación y de lectura, según el lector pueda modificar (hiperficción constructiva o escritura colaborativa) o no (hiperficción explorativa) los textos que lee; del otro, podemos atender al tipo de contenido que incluyen, que puede ser meramente textual (hipertexto) o también visual o auditivo (hipermedia). El cruce de ambas tipologías nos permite distinguir cuatro categorías básicas: (1) hiperficción explorativa hipertextual, (2) hiperficción explorativa hipermedia, (3) hiperficción constructiva hipertextual e (4) hiperficción constructiva hipermedia.

En lo que respecta a la (1) hiperficción explorativa hipertextual, en la que los lectores no pueden modificar unas obras que incluyen sólo un contenido textual, nos encontramos con «hipernovelas» como Sinferidad (2000), de Benjamín Escalonilla, donde el lector puede ir alternando la lectura de los monólogos de dos personas que van en moto; o Como el cielo los ojos (1995) de Edith Checa, donde el lector puede escoger entre leer cualquiera de los trece momentos o tiempos de los monólogos de tres personajes que reaccionan de formas diversas ante la muerte de una mujer, de la cual uno de ellos había sido su marido, y los otros dos, sus amantes.

A medio camino entre la hiperficción explorativa hipertextual y la hiperficción explorativa hipermedia, nos encontramos con una hipernovela como Condiciones extremas (1998), de Juan B. Gutiérrez y Giovanni Castro, donde se combina la novela tradicional con la novela gráfica. Desde un principio, el lector tiene la opción de leer sólo el texto (de Gutiérrez), sólo las ilustraciones (de Castro), o la combinación de ambos. Pensando en la dificultad de una lectura no lineal, el autor ofrece al inicio un «Argumento», en el que se dibujan las líneas maestras de la historia, así como un «Mapa», en el que se listan todos los espacios de texto, ordenados de forma cronológica, por si el lector prefiere una lectura más lineal. La historia, que pertenece al género de la ciencia ficción, se desarrolla en Bogotá, durante los años 1998, 2050 y 2090, e incluye razas mutantes, problemas ecológicos y viajes en el tiempo.

En lo que respecta a la (2) hiperficción explorativa hipermedia, nos encontramos con «novelas hipermedia», «webnovelas», o «blognovelas», también llamadas «blogonovelas», que los lectores tampoco pueden modificar, pero que incorporan, mediante enlaces, fotografías, vídeos, audios, blogs o páginas webs. Entre las novelas hipermedia pueden hallarse títulos como Tierra de extracción (20012007), de Doménico Chiappe y Andreas Meier; Wordtoys (2006), de Belén Gache; Heartbeat (1999), de Dora García; Golpe de gracia (2006), de Jaime Rodríguez; o Una contemporánea historia de Caldesa (2007), de Félix Remírez. En esta última, el lector puede leer, saltando de una a otra, la historia de cuatro personajes: Joan, Caldesa, Rois y Aurora. En el texto, algunas palabras remiten al lector a imágenes, archivos de audio, vídeos o páginas web que los ilustran, amplían o redireccionan. La lectura no es lineal y, además, el lector debe esperar a que pase el tiempo -un tiempo acelerado, eso sí, para no dificultar demasiado la lectura, tal y como puede constatarse por el reloj que aparece en la parte inferior de la pantalla- para saber cómo evoluciona la historia de estos personajes. La posición del lector «es la de un espectador que está sobrevolando la vida de los personajes y es capaz de saber lo que les acontece, pero que no puede detener su vida ni retrasar los eventos que se narran» (Remírez, 
2007: html). De este modo, «la vida de los personajes se nos aparece independiente y dinámica. Fluye por sí misma y sólo podemos seguirla o dejarla pasar» (Remírez, 2007: html). Por otra parte, paralelamente a la trama principal, de vez en cuando se abren pequeñas ventanas adicionales en las que se pueden leer fragmentos de la obra original, en catalán.

Un ejemplo de «webnovela» sería Don Juan en la frontera del espíritu (2006), de Juan José Díaz, una webnovela histórica que narra las vivencias políticas y amorosas de Juan Valera durante su embajada en el Washington de la Gilded Age. En el primer capítulo, por ejemplo, palabras como «niebla», «trasatlántico»o «muelle» nos remiten a fotografías antiguas donde aparecen dichas realidades; la palabra «sirena», a un archivo de audio en el que se oye la sirena de un barco; la primera mención -indirecta- al personaje de Juan Valera, a una biografía del mismo, escrita por Enrique Rubio Cremades, y albergada en la Biblioteca Virtual Cervantes; y la palabra «Ateneo», a la página web actual del Ateneo de Madrid. Según dice Díaz en la introducción, el lector puede (1) «leer cada capítulo sin atender a los links, navegándolos después», sería la lectura tradicional; (2) «leer entrando en cada enlace a medida que vayan apareciendo», regresando a continuación al texto, lo que equivaldría a la lectura «de una novela profusamente ilustrada»; o (3) «detenerse en cada link, conectar con todos los que aparezcan y perderse». Este último tipo de lectura sería más caótica, aunque el autor considera que es la verdadera «experiencia webnovela» (Díaz, 2006: html).

Por su parte, las blogonovelas o blognovelas suelen recurrir a ficciones en primera persona, en las que la forma testimonial, epistolar o diarística aprovecha de forma muy orgánica el sistema de entregas periódicas de los blogs. Según Escandell, quien realiza un extenso estudio del género, en Escrituras para el siglo XXI. Literatura y blogosfera (2014), los antecedentes de la blogonovela se hallan ya en la expansión del folletín francés (180), si bien ésta no existirá realmente hasta el advenimiento de internet, en general, y de los blogs en particular. Por otra parte, no basta con que una novela haya sido escrita y difundida mediante entradas de blog para que sea considerada una blogonovela, sino que debe presentar toda una serie de características muy particulares. Según Casciari, «se trata de una obra escrita en primera persona, donde la trama ocurre siempre en tiempo real», de modo que «no son válidas las extrapolaciones, ni un transcurso del devenir diferente al de la fecha de publicación»; asimismo, «el protagonista se reconoce como gestor del formato (el weblog), la realidad afecta al devenir de la trama, el protagonista «existe» fuera de la historia» $\mathrm{y}$ «el autor no aparece nunca mencionado dentro del territorio de la ficción» (2006: 172-173). Según Escandell, en la blogonovela no hay lugar para un yo autor, sino solo para el yo personaje, y, además, el autor apenas tiene unos segundos para convencer al lector potencial de que se quede en su espacio, lo que supone argumentos sencillos, escritura verosímil, extensión comedida y frescura (2014: 184-187). Este tipo de características han llevado a diversos estudiosos a criticar la calidad estructural de las blogonovelas (cf.: Escandell, 2014: 187-192), si bien existen otras miradas más inclusivas (192-195). A este tipo de escritura, más íntima y cercana, se le añade el hecho de que los comentarios de los lectores, o visitantes casuales, pueden completar o, incluso, modificar el plan general de la obra. 
Una de estas blogonovelas es Weblog de una mujer gorda, de Hernán Casciari, que fue publicada en 200 entregas desde septiembre de 2003 a julio de 2004, si bien luego fue publicada en papel por Plaza \& Janés bajo el título Más respeto que soy tu madre (2005). Esta blogonovela, que ganó el concurso de weblogs de la cadena alemana Deutsche Welle, y fue transformada en una existosa obra de teatro, narra, a través de los ojos de un ama de casa argentina de cincuenta años, la historia de una familia argentina desestructurada durante la crisis económica de 2001.

En la blogonovela Detective bonaerense (2006), de Marcelo Guerrieri, un detective llamado Aristóbulo García publica en un blog sus notas de investigación. El lector puede leer las entradas a medida que el detective-narrador las va colgando, lo que implica un ritmo de lectura muy lento -casi simultáneo con el de la creación-, o leerlas sin interrupción, ya después de haber sido publicada íntegramente. El texto contiene multitud de enlaces que remiten al lector tanto a otras entradas del blog, como a canciones, imágenes, webs o entradas de diccionario o enciclopedia, con las que puede ampliar su comprensión o imaginación del texto. El blog contiene también varios apartados en los que se incluyen fotografías de pistas, así como la transcripción de las declaraciones de varios de los personajes, siempre con el objetivo de estimular la imaginación y la especulación del lector. A todo esto se le añaden los comentarios que los lectores del blog han ido realizando acerca de la novela, si bien, en la mayor parte de las ocasiones no juegan a participar de la historia -tratando de resolver el caso, por ejemplo-, sino, simplemente, a emitir su opinión acerca de la calidad o interés de la novela.

En lo que respecta a la (3) hiperficción constructiva o escritura colaborativa hipertextual, donde los lectores tienen la opción de modificar los textos que leen, podemos distinguir entre novelas colaborativas, novelas colectivas y wikinovelas. Las novelas colaborativas están escritas por un autor determinado, si bien aceptan una cierta colaboración por parte del lector, que puede modificar, agregar o, incluso, eliminar fragmentos. Tal sería el caso de El libro flotante de Caytran Dölphin (2006), de Leonardo Valencia, cuya versión digital, de corte colaborativo, fue realizada por Eugenio Tisselli. En dicha novela, el protagonista, Iván Romano, narra la historia de un escritor ficticio llamado Caytran Dölphin, llegando a citar y comentar hasta 56 fragmentos de su novela, también ficticia, intitulada Estuario. En la versión de Eugenio Tisselli, los lectores, a los que se les da el nombre de «lectonautas», pueden colaborar en la reproducción completa -y apócrifa- de Estuario. Para guiar al lector, en la web se reproducen los fragmentos de Estuario, junto con los comentarios de Iván Romano, ya incluidos en la versión impresa, a los cuales se les van añadiendo los nuevos fragmentos apócrifos elaborados por los lectores. Éstos tienen la oportunidad de reescribir los fragmentos incluidos en la web usando alguno de los tres siguientes tipos - combinables- de distorsión: distorsión por substitución -de una sola palabra del fragmento-, distorsión completa - de todas las palabras de un fragmento- o distorción por edición -opción en la cual el lector puede editar libremente el texto del fragmento-.

Las novelas colectivas suelen estar escritas por un conjunto de varios autores, normalmente coordinados y editados por uno de ellos, que suelen escoger de antemano unas ciertas líneas estilísticas, narrativas y genéricas, y utilizar algún tipo de soporte digital que facilite la tarea de edición, como, por ejemplo, un blog o un editor de textos en línea. Tal sería el caso de Milagros sueltos (2007), dirigida 
por Dorelia Barahona, que fue publicada bajo la forma de entradas de un blog en el que cada uno de los autores (Dorelia Barahona, Pedro Pablo Viñuales, Floria Bertsch, Janina Bonilla, Víctor Valdelomar, Catalina Murillo y Jaime Ordóñez) se ocupaba de un personaje diferente. Según puede colegirse de las respuestas de varios de los autores a los comentarios que algunos lectores hacen al final de la primera entrega, el grupo de autores eligió a la coordinadora, que dirigió y editó la obra, respetando los diferentes estilos; acordaron una cierta coherencia estilística, narrativa y genérica; y apostaron por un proceso de creación horizontal, pudiendo cada autor recomendar cambios o ajustes en las partes de los otros autores, quienes, a su vez, podían aceptarlos o rechazarlos libremente.

La wikinovela es un subtipo de novela colectiva, que se caracteriza por utilizar el sistema wiki (que en hawaiano significa «rápido») de edición de páginas web, gracias al cual éstas pueden ser editadas directamente desde el navegador por cualquier persona. Normalmente, el número de autores de una wikinovela es muy superior al de una novela colectiva, y, además, suelen ser anónimos. Tal sería el caso de Wikinovela (http://www.wikinovela.org/), un experimento de creación narrativa colectiva, multilingüe (castellano, vasco e inglés), no lineal y abierto al público, desarrollado por la facultad de Filosofía y Letras de la Universidad de Deusto, del País Vasco. Este experimento duró, en su primera etapa, del 24 de abril al 24 de julio de 2006, dando lugar a una wikinovela que acabó titulándose Vidas prodigiosas. Se trata de una novela «polivalente, pues cada nuevo hiperlink abre una nueva cadena de secuencias», lo cual la hace muy dinámica y a la vez debilita la tensión interna del relato (Alayón Gómez, 2009: html). Otras wikinovelas serían Madrid escribe (2006), que partía de un primer capítulo escrito por Lorenzo Silva, al que se añadieron seis capítulos que un jurado escogió de entre todas las propuestas de continuación que se enviaron; y El regreso de Cecilio (sin fecha), albergada en el portal de escritura colaborativa Wikia, y que es un ejemplo de ciencia ficción, de tono ciberpunk.

La (4) narración constructiva o colaborativa hipermedia permite que los diversos autores que participan en ella añadan al hipertexto todo tipo de elementos multimedia, como archivos de audio, fotografías, vídeos, animaciones o GIFs. De este modo, en la novela hipermedia se disuelve la centralidad que la palabra todavía mantiene en la novela hipertextual, dando lugar a una experiencia creadora y lectora cualitativamente diferente. Tal sería el caso de La huella del cosmos (2005), una novela hipermedia colectiva dirigida por Doménico Chiappe, donde la narración puede avanzar mediante todo tipo de mecanismos multimedia y, además, el usuario puede escoger entre simplemente explorar, siempre de forma azarosa, el contenido de la novela, o contribuir a su escritura mediante diversos modos de interacción.

Cabe preguntarse, por otra parte, de qué modo el mundo emergente de los videojuegos, que está asumiendo de formas muy interesantes y creativas elementos de otros ámbitos, como el cine (bandas sonoras, guiones, iluminación) o la literatura (novelas que completan el imaginario del videojuego, como sucede, por ejemplo, con World of Warcraft o los Sims), podría algún día subsumir el mundo de la creación literaria. En realidad, ya se han dado algunos pasos en esta dirección. Patricio Pron analiza, en «La parte real / Jugando a escribir una novela (en lugar de escribirla)» (Prodavinci, 11/02/2016) 
dos videojuegos que tienen como protagonistas a escritores: Alan Wake (dir. Moises Rodolfo, 2010) y The Novelist (dir. Kent Hudson, 2013). Lo cierto es que, mientras que el primero deriva rápidamente en un juego de acción, sin explorar realmente la actividad literaria de su protagonista, el segundo sí toma como elemento central el proceso de escritura, siendo el objetivo del jugador tomar las decisiones necesarias para que el protagonista del juego, el novelista Dan Kaplan, pueda completar los nueve capítulos de su novela. El videojuego parece tener un potencial literario importante, si bien, en opinión de Patricio Pron, «la escritura de la novela no ocupa prácticamente ningún lugar en The Novelist, pese a que se supone que todo gira alrededor de ella»; sin contar «la puerilidad de las decisiones que el jugador tiene que tomar por Dan» (11/02/2016: html). Eso no impide que éste sea un camino a explorar, que quizás algún día pueda suponer una verdadera competencia al boom actual de las escuelas de escritura.

Cabe añadir un quinto tipo de ciberliteratura, relacionada con las redes sociales, a la que podríamos llamar (5) ciberliteratura social. Comencemos constatando que las facilidades técnicas para incluir modalidades narrativas no textuales, como los archivos de audio, imagen o vídeo, ha hecho que la ciberliteratura centrada en la mera experiencia textual sea cada vez más escasa. Recordemos que no estamos hablando de lo digital como mero soporte, esto es, del ebook o libro digital, un ámbito que continúa, con parones, su imparable evolución; nos referimos, más bien, al hecho de que el auge de las redes sociales ha supuesto una cierta renovación de la ciberescritura.

Tal sería el caso de la llamada «tuiteratura», que no debe reducirse al mero microrrelato, ya que no se trata sólo de que su extensión no pueda sobrepasar los 140 caracteres, sino también de que se juegue con elementos propios del canal, como los hashtags, retweets, likes o también fotografías, memes o audios - lo que lo acercaría a la literatura hipermedia-, y de que el mismo contenido del relato incluya todo un imaginario relacionado con las redes sociales. Este tipo de escritos pueden llegar a ser publicados, después, en formato de libro, en papel o en formato electrónico. Tal es el caso, por ejemplo, de Selected Tweets (2015), una selección de los tweets que Tao Lin y Mira Gonzalez escribieron en sus diferentes cuentas de Twitter entre el año 2008 y el 2015. Por otra parte, tal y como nos informa Patricio Pron, en su artículo «Marca un poema o tuitéalo», el género de la tuitnovela por entregas florece en Japón, donde estas novelas suelen ser éxitos de ventas entre los adolescentes (El País, 26/03/2016).

Lo mismo sucede, aunque en menor medida, con la publicación, primero en línea y luego en papel o libro electrónico, de los estados de Facebook, que muchos escritores han comenzado a utilizar como dietario, anecdotario o libreta de apuntes. Tal sería el caso de un libro como Listen to me (La Bella Varsovia, 2013), donde se recogen los estados y conversaciones que Manuel Vilas publicó en Facebook de 2008 a 2013. Cabe señalar que en este tipo de obras predomina la tendencia general a la autoficción, en virtud de la cual se suelen borrar los límites entre el autor, el narrador y el personaje, que tienden a compartir el mismo significante -el nombre propio-, aunque no siempre el mismo 
referente, pues lo que se predica del narrador o el personaje no siempre coincide con la vida o la persona del autor real ${ }^{5}$.

\section{2. Ciberensayo}

El género del ensayo es, en sus orígenes, el más cibernético de todos los géneros. Para empezar, el término cibernética procede del término griego kybernêtikê, que hace referencia al arte de conducir una nave, si bien luego se usó para hacer referencia a la navegación mediante enlaces o links que nos remiten a otros textos, archivos o páginas webs. Lo cierto es que este tipo de lectura salteada está en el origen mismo del género del ensayo, lo que explicaría que se trate del género estructuralmente más armónico con los nuevos modos de ciberescritura y ciberlectura. A diferencia de los demás géneros, el género del ensayo, al menos en su versión moderna -que no debe ser confundida con el de la miscelánea o tratado de las épocas antigua y medieval- tiene un origen perfectamente conocido: los Ensayos (Burdeos 1580 y París, 1588) de Michel de Montaigne. Este género, que se halla en el cruce entre las memorias, el diario, la correspondencia, el tratado y la miscelánea, nace como un diálogo con las citas que éste se hizo grabar en las vigas de su biblioteca y los pasajes que seleccionaba al azar en los volúmenes que ésta contenía. Tanto es así que podría realizarse, utilizando la forma de hipertexto, una edición crítica y genética de los Ensayos, sin que el resultado final presentase demasiadas diferencias estructurales con respecto a un blog 6 .

Paradójicamente, la afinidad estructural entre el ensayo y el hipertexto, en general, o el blog, en particular, parece haber supuesto un freno a la consolidación del género del ciberensayo. Ciertamente, más allá del sistema de enlaces y los contenidos hipermedia, el mundo digital no implica todavía una renovación suficientemente radical de este género, desde un principio «cibernético», como para que un ciberensayo no se vea, simplemente, como un ensayo pasado a formato digital, ya sea ebook, ya sea blog. Como sucedía con la blogonovela, no basta con que un ensayo sea pasado a formato digital para que lo consideremos un ciberensayo, sino que debe cumplir, o por lo menos explorar, ciertas características específicas, como, por ejemplo, el uso del hipertexto, la incorporación de archivos hipermedia o el formato colaborativo. Es significativo que el género del ciberensayo, propiamente dicho, no haya sido utilizado tanto en el ámbito literario como en el educativo, Pueden consultarse algunos ciberensayos de intención pedagógica en la página mydocumenta.com, donde se albergan diversos trabajos de síntesis de bachillerato diseñados bajo la forma de página web ${ }^{7}$. Cabe señalar, sin embargo, que un programa de presentación digital como, por ejemplo, prezi.com, presenta una gran potencialidad de cara a la creación de ciberensayos, en virtud de su capacidad para distribuir topológica y dinámicamente los pensamientos, así como para albergar contenidos hipermedia.

\footnotetext{
${ }^{5}$ Sobre el concepto de autobiografía y autoficción pueden consultarse las obras fundamentales de Lejeune (1994), Alberca (2007) y Casas Janices (2014).

${ }^{6}$ Sobre los orígenes del ciberensayo, véase Cuesta (2003), sobre el ciberensayo, en general, Landow (2006: 440-442) y Escandell (2014: 27).

${ }^{7}$ Sobre el tema del hipertexto informativo, véase el artículo «Necesidades de formación y experimentación. El hipertexto informativo», de Rodríguez de las Heras (2004: 75-86).
} 
Sin embargo, el soporte más habitual del ciberensayo son los diarios digitales, los blogs y las redes sociales. Las plataformas más célebres actualmente para la confección de diarios digitales son Livejournal.com, Diary.com o Penzu.com, que aceptan contenido hipermedia, y pueden ser privados o públicos, siendo su principal novedad «la mezcla de lenguajes» (Carrión, 2015: html). Por su parte, los blogs que han sido estudiados por Daniel Escandell, en Escrituras para el siglo XXI. Literatura y blogosfera (2014), se caracterizan por la periodicidad, el diálogo con el lector, el orden cronológico y las relaciones con otras redes sociales, ha tenido en los últimos años un gran auge, dando lugar a una auténtica galaxia literaria conocida como «blogosfera», término creado en inglés por Brad L. Graham, en el año 1999, si bien fue popularizado por William Quick, en el año 2001. La volatilidad de la blogosfera, en la que millones de blogs aparecen y desaparecen constantemente, mientras otros son de contenido privado o se hallan en estado de relativa hibernación, pues llevan meses sin actualizar sus contenidos, hacen que sea «un constructo canónico imposible de fijar» (Escandell, 2014: 29-30). Por otra parte, tras la gran explosión demográfica de los blogs, a finales de los noventa y primera década del siglo XXI, nos encontramos con que ha habido un «decrecimiento del 23,8\% de las personas que leen blogs» (Fundación Telefónica, 2012: 34). Sin embargo, Escandell, a pesar de conceder que ha desaparecido el aura de fascinación que produjo en su principio el blog, atempera la muerte anunciada del blog, considerando que dicha forma está, en todo caso, mutando o fusionándose con otras más nuevas (150).

En lo que respecta a las redes sociales, muchos escritores utilizan los estados de Facebook o los tweets como dietario - tal sería el caso de la escritora Aixa de la Cruz, según la cual «mi dietario es Facebook» (cit. en Carrión, 2015)- o como repositorio de reflexiones políticas, consideraciones personales o diálogos con aquellos seguidores que comentan sus estados. Tal sería el caso, por ejemplo, del artista Ai Wei Wei, que comenta por medio de tweets sus performances en tiempo real -véase al respecto «Ha nacido la tuiteratura» (García, 12-05-2013: html)-.

Se ha hablado mucho acerca del narcisismo exhibicionista que este tipo de géneros recoge y, a la vez, cataliza. En los últimos tiempos se ha generalizado el término «extimidad» para hablar de «la necesidad compulsiva de autoexposición pública de la privacidad» (Escandell, 2014: 25). Según estudia Paula Sibilia, en La intimidad como espectáculo (2008), la extimidad ha supuesto un cambio de paradigma en la forma de construir la propia identidad, que ha pasado a depender más de la mirada ajena. No se trata sólo, como explican Pérez-Lanzac y Rincón (24/03/2009), de que la autoexposición nos lleve a fingir quienes somos, sino de que nos lleva realmente a pensar, sentir y, en definitiva, ser de otra manera, como si fuésemos fotones que, en virtud del principio incertidumbre, se comportan de forma diferente si son o no observados. Autores como Lipovetsky y Charles han relacionado la extimidad con el narcisismo propio de la cultura del capitalismo tardío (2006: 27); o Illouz considera, en Intimidades congeladas (2007), que el «capitalismo emocional» ha convertido la propia intimidad en una mercancía. 
Otro género reciente, conectado, de algún modo, con el ciberensayo, es el género de los memes de Internet ${ }^{8}$, frases persuasivas, motivadoras, reflexivas o cómicas, acompañadas de una imagen o algún otro tipo de ilustración multimedia, y que alcanzan una gran difusión gracias a las redes sociales. Aunque la calidad de estas expresiones es muy variada, y suele caer en el chiste craso o en la mera literatura de autoayuda, se trata de un formato que entronca con antiguos géneros visio-literarios, como la emblemática barroca o las vidrieras de las catedrales, y prefigura nuevos modos de vivir la escritura y la lectura. Ciertamente, del mismo modo que Erasmo se animó a antologar un género despreciado en su época, como era el del refrán o el adagio, no es imposible que aparezca algún día una teoría y una práctica realmente literaria o filosófica de los memes.

\section{3. Ciberpoesía}

Señalemos nuevamente que, al usar el término «ciberpoesía», no nos referimos a aquellos poemas escritos en papel que luego han sido pasado a soportes digitales, sino a poemas pensados, desde el mismo momento de su creación, con la intención de aprovechar todas las posibilidades poéticas que los medios digitales y cibernéticos ofrecen. La piedra de toque para saber si un poema es realmente un ciberpoema sería que no puede ser simplemente leído o impreso en hoja de papel, pues el soporte digital se habría convertido en una parte esencial del poema. Cabe señalar, sin embargo, que esto supone una gran diferencia, y quizás una gran limitación, respecto del género poético tradicional, para el cual es esencial la recitación, la musicalización y la memorización.

Como sucedía con el género del ensayo, que desde sus inicios mismos prefiguraba algunos de los elementos fundamentales del ciberensayo, el género de la poesía contempla en su propia naturaleza -fragmentada, experimental y sinestésica-, todas las posibilidades de la ciberpoesía, poesía electrónica o poesía digital. Podría decirse que, frente a la blognovela o la webnovela, que siempre podrán sorprendernos, un ciberpoema siempre hallará algún tipo de antecedente en tiempos más o menos remotos, como, por ejemplo, la poesía abstracta, la poesía visual, la poesía concreta, el «cadáver exquisito», el centón o la performance poética.

No es extraño, pues, que la ciberpoesía haya adoptado rápidamente una gran variedad de formas, y que sea prácticamente imposible cerrar una clasificación. En todo caso, siguiendo los tres volúmenes de la Colección de Literatura Electrónica (http://collection.eliterature.org/), publicados en 2006, 2011 y 2016, por la Electronic Literature Organization, podemos aventurar la siguiente tipología9

1. Poesía hipertextual: Aunque este tipo de poesía está centrada fundamentalmente en la palabra, tiende a usar el hipertexto para fomentar una lectura no lineal. Tal sería el caso de una obra como Intermínimos de navegación poética (edición catalana de 1996, española de 1999 y tetralingüe, con el inglés y el francés, de 2005), una fusión hipertextual en línea de los poemarios Poemes mínims (1995) -en hipertexto integral- y Cima branca (1995) - en texto lineal-, de Ramon Dachs. En dicha

\footnotetext{
${ }^{8}$ El término «meme» es un neologismo acuñado por Richard Dawkins, en su libro El gen egoísta, por semejanza fonética con los términos «gen», «memoria» y «mímesis», para dar cuenta de su teoría de la transmisión cultural.

${ }^{9}$ Véase también Corral Cañas (2012: 11-17).
} 
obra, algunas palabras clave -como «agua», «tierra», «flor»o «luz»- nos remiten a otros versos en las que esas mismas palabras aparecen también enlazadas, permitiendo, de este modo, a cada lectura, componer un nuevo poema con una cierta coherencia semántica. Otro ejemplo de hiperpoema es «About Stained Word Window» (1999), de Deena Larsen, en el que el lector, puede mover el ratón sobre el poema, provocando que las palabras cambien y se desvanezcan, o pulsar alguno de los enlaces, saltando, de este modo, a alguno de los trece nodos poéticos que lo componen.

2. Poesía visual: La poesía visual puede ser verbal, en el sentido de que todavía emplea de forma significativa signos gráficos -palabras sueltas, sílabas, números o signos matemáticos-, o no verbal, cuando dichos gráficos son usados con una intencionalidad meramente estética, como formas sugerentes sin un significado específico, sea literal o simbólico. Por otra parte, este tipo de poesía suele ser poesía animada, en la que las letras, palabras o versos se mueven por la pantalla, ya sea de forma programada, ya sea mediante la participación del lector, que se transforma, de este modo, en lectoautor. Puede hallarse un ejemplo de poesía visual animada no interactiva en Tipoemas y Anipoemas (19972003), de Ana María Uribe, y un ejemplo de poesía visual animada interactiva en Velo City (2000), de Tina Escaja, que evoca la movilidad vertiginosa de los internatuas en el ciberespacio, y en la que el lector puede pulsar sobre algunas palabras haciendo que se muevan, desaparezcan, desintegren o recompongan.

3. Poesía holográfica u holopoesía: Este tipo de poesía, creada en 1983 por Eduardo Kac (http://www.ekac.org/allholopoems.html), con el apoyo técnico de Fernando Catta-Petra, aprovecha la técnica holográfica para representar de forma tridimensional todo tipo de letras, palabras, versos y figuras, con la intención de trascender la vivencia monoscópica de la poesía tradicional.

4. Poesía programada o automática: Este tipo de poesía es generado de forma automática por programas a los que se les ha dotado de un vocabulario y unas reglas de composición. A pesar de ser automática, el lector puede interactuar con el programa, en mayor o menor medida, pudiendo alterar algunos parámetros de composición o introduciendo nuevos elementos léxicos. Pueden encontrarse ejemplos en la web titulada Poesía asistida por computadora (2006), de Eugenio Tisselli o en www.rimador.net Existen también generadores de poemas paródicos, como, por ejemplo, el «generador de poemas lorquiano» o el «generador de poesía barata», si bien, debido a la volatilidad de Internet, no siempre son fáciles de encontrar.

5. Poesía virtual: Este tipo de poesía utiliza gafas de realidad virtual o carboards VR (Virtual Reality) para evocar, mediante la técnica de la realidad virtual, poesías tradicionales o poemas nuevos, utilizando específicamente las potencialidades específicas de este medio. Así, a las virtualidades de la poesía verbal, se añade la posibilidad de ver paisajes y espacios en 360 grados, así como la de interactuar con objetos invocados por la poesía en cuestión. Tal sería el caso de War of Words (2014), un videojuego-poema, diseñado para Android e iOS, en el que el usuario-lector se pone en la piel del poeta Siegfried Sassoon, para vivir en primera persona su poema de guerra «El beso», utilizando todo el potencial de la realidad virtual. 
6. Wikipoema: Como sucedía con el caso de la wikinovela, el wikipoema utiliza el sistema wiki de edición de páginas web, que permite que cualquier persona pueda editar directamente desde su navegador el verso o poema propuesto inicialmente. No es extraño que el antecedente del wikipoema sea el «cadáver exquisito», practicado por los surrealistas, puesto que, a menos que exista un trabajo muy consciente de coordinación y edición, los wikipoemas suelen derivar en el absurdo, sin dejar de ser, por ello, interesantes. Pueden leerse el wikipoema Poepedia (2014), de la mexicana Karen Villeda, o la selección de wikipoemas ingleses incluidos en http://wikipoetry.tumblr.com/

\section{4. Ciberdrama}

A diferencia de la cibernarrativa, el ciberensayo o la ciberpoesía, el ciberdrama no contempla tanto el uso del hipertexto o el contenido hipermedia como, directamente, el uso de técnicas de realidad virtual. Según Abuín, «la realidad escénica, avalada por siglos de experiencia comunicativa y semiótica muy definida» no se ha salvado del contagio digital, «sin duda porque el teatro siempre ha gustado de desestabilizarse a sí mismo con la incorporación de lo nuevo» (2008: 31). No es extraño, pues, que el teatro no haya opuesto ninguna resistencia a la inclusión de nuevas tecnologías, tal y como estudia Steve Dixon, en Digital Performance (2007), donde se habla de teatro de robots, teatro con Realidad Virtual, teatro con proyecciones digitales manipulables, performances telemáticas, videojuegos y obras de net.art.

El ciberteatro suele adoptar alguna de las siguientes formas:

1. Teatro interactivo, en el que las técnicas digitales se ponen al servicio del célebre lema de Allan Kaprow, que introducía la necesidad de hacer participar al espectador de la obra: «Go in instead of look at» (cf. Abuín, 2008: 38-41).

2. Teatro virtual, donde entran hipertextos, videojuegos, MUDs, MOOs o teatro que utiliza la realidad virtual, mediante el uso de cascos catódicos.

3. Teatro de realidad aumentada, «donde el cuerpo físico de los actores se combina con la proyección de diapositivas y vídeo sobre grandes pantallas divididas y con los efectos digitales de última generación, que crean cuerpos virtuales o avatares para el espectador» (Abuín, 2008: 42-44).

El ciberdrama está estrechamente conectado con la ludología, que estudia las potencialidades del mundo digital para ofrecer, de una forma muy semejante a la que ya adoptan los videojuegos, una vivencia más directa, real e interactiva de mundos e identidades alternativos, tal y como estudió Janet Murray en un libro ya clásico, titulado Hamlet en la holocubierta: el futuro de la narrativa en el ciberespacio (1998). En este sentido, podrían ser considerados ciberdramas los mundos y vidas paralelas que muchos cibernautas han construido en juegos como Myst, Los Sims, Second Life o World of warcraft.

En lo que respecta al teatro de robots, son interesantes las consideraciones de Teresa López Pellisa (2013b: 219-234), quien afirma que la principal diferencia entre el teatro de robots y el de marionetas, en el que aquél encuentra su origen, se halla en que el primero «no siempre está dirigido 
en tiempo real por un humano, como el muñeco o el títere, ya que puede estar programado para realizar el espectáculo de manera autónoma» (219). Dejando a un lado sus antecedentes, que se remontan, en lo teórico, a la época grecolatina y, en lo práctico, a los autómatas de los siglos XVII y XVIII, el teatro de robots nace en el siglo XX, con el uso de tecnoactores como tecnotíteres - «aquellos robots con movimiento programado, pero cuyo movimiento o cuya voz están interpretados por un actor profesional humano en tiempo real»(225 y 226-229)-, roboactores - «seres artificiales cuya interpretación es absolutamente autónoma (condicionada por un software programado previamente), aunque suelen interactuar con autores humanos»(225 y 229-233)- y autómatas - «artefactos de movimiento autónomo, antropomorfos o no, cuyo sonido y movimiento son independientes a la acción de un humano en tiempo real» (225-226)-.

Con todo, tal y como señala Abuín, «las nuevas tecnologías aplicadas al teatro, todavía llaman demasiado la atención sobre sí mismas como medio o dispositivo» (2008: 31), con lo cual debemos esperar un poco a que el teatro pueda asimilar de forma más natural este tipo de recursos, del mismo modo que, en su momento, tuvo que asimilar los coturnos o el deus ex machina ${ }^{10}$.

\section{Ciberlectura}

La era digital no sólo ha variado los hábitos de escritura, sino también los de lectura. No se trata, sin embargo, de la primera vez que se producen cambios en la historia de la lectura tradicional. Si nos remontamos a los inicios, el primero de todos estos cambios fue la aparición misma de la escritura y la lectura, que supuso una verdadera revolución en los modos tradicionales de adquirir y almacenar la información, y que despertó entusiasmos y recelos muy semejantes a los que hoy día despierta la ciberlectura. Ciertamente, hasta la aparición de la lectura, el modo principal de adquirir la información era la experiencia directa o el relato de personas que habían tenido a su vez una experiencia directa. No es extraño, pues, que la aparición de la escritura fuese vista como una amenaza para los modos de conocimiento y de cultura, como queda, de algún modo, reflejado en el Fedro (274c-277a y 279b279c), de Platón, quien pone en boca de Sócrates un discurso contrario a la escritura, entre cuyos argumentos domina la idea de que ésta acabará con la memoria, así como con la vitalidad dialéctica de los pensamientos, relatos y conversaciones.

Más allá del texto platónico, sabemos que con la aparición de la escritura y la lectura, hacia el cuarto milenio antes de cristo, se produjo un cambio radical, no sólo en nuestra cultura, sino también en nuestros modos de pensar. En efecto, los nuevos hábitos lectores exigieron que el cerebro se reestructurase, con el objetivo de interpretar argumentaciones más complejas, y asimilar un gran número de datos que no era posible ni deseable recordar. No debemos pensar, sin embargo, que, una vez asimilada la revolución del nacimiento de la lectura tradicional, ésta ha continuado inalterada hasta el advenimiento de la lectura digital. Lo cierto es que a lo largo de estos cinco milenios se han

\footnotetext{
${ }^{10}$ Sobre la condición teatral o no teatral del ciberteatro, véase López Pellisa (2013a: 24-39).
} 
producido otros muchos cambios, que despertaron, a su vez, esperanzas paradisíacas y recelos apocalípticos.

Tal fue el caso, por ejemplo, de la aparición de la lectura a voz baja, ya registrada a finales del siglo IV, en un célebre pasaje de las Confesiones (VI, 3) de San Agustín, en el que el de Hipona se sorprende al ver a San Ambrosio leer en silencio. Este tipo de lectura permitía una mayor interiorización, meditación, reflexión y, lo que también podía verse como un problema, libertad de diálogo con el texto ${ }^{11}$. En los siglos XII y XIII, se generalizó la separación entre las palabras y el uso de los signos de puntuación; transformaciones que hicieron mucho más ligera y accesible la lectura. Este cambio supuso una cierta democratización de la lectura en un mundo en el que una burguesía naciente había tenido que aprender a leer para manejarse en el mundo del comercio.

Este proceso de democratización de la lectura culminaría con la invención de la imprenta, por Johannes Gutenberg, a mediados del siglo XV. Como puede imaginarse, el hecho de que las grandes obras de la religión y el pensamiento pasasen a estar al alcance de los ciudadanos supuso un cambio revolucionario. Quizás el más importante fue que el monopolio interpretativo de las Sagradas Escrituras, que la Iglesia había detentado durante más de un milenio, fue contestado por la lectura directa, que había pasado a estar al alcance de muchos. Dicho proceso colaboró, indudablemente, con el cisma religioso, que Lutero culminó a principios del siglo XVI. Ciertamente, para una Europa que conservaba todavía muchos aspectos medievales, la idea de que el saber, o lo que ellos consideraban la degradación del saber, se difundiese por todo el pueblo, fue sentido como una decadencia cultural, una degradación religiosa y un peligro político.

Dejando a un lado la aparición de la prensa, en el siglo XVIII -si bien su generalización tendrá lugar a lo largo del XIX-, la siguiente gran revolución del mundo de la lectura y la escritura después de la invención de la imprenta ha sido la aparición de los soportes digitales y/o conectados de lectura. Como en el apartado anterior, distinguimos entre lectura digital, que tiene lugar en un soporte digital no conectado, como es el caso del $e b o o k$, que usa la tinta electrónica y permite un gran almacenamiento de obras, si bien no supone una revolución profunda del modo de leer, que sigue siendo lineal; y la ciberlectura, que, en virtud de la conexión a internet, el uso del hipertexto y la interacción colaborativa del lector, que pasa a ser usuario, sí ha supuesto una modificación radical en los modos de leer.

\section{1. Lectura digital}

Empecemos viendo cuáles han sido las modificaciones que la lectura digital, en cualquiera de los formatos de ebook o libro electrónico, ha operado en los hábitos tradicionales de lectura. Empecemos señalando que la lectura en pantalla no es tan reciente como suele creerse. En realidad, este cambio empieza a operarse ya desde que aparecen los primeros ordenadores, si bien es cierto que

\footnotetext{
${ }^{11}$ Véase al respecto la Historia de la lectura (1996) de Alberto Manguel, Nadie acabará con los libros de Eco y Carrière (2010: 102-103) y «Un informe sobre la lectura», de Eduardo Mendoza (2006: html).
} 
su generalización ha tenido que esperar a que la técnica hiciese su lectura más cómoda y menos fatigosa.

Quizás el primer gran cambio que la aparición de la lectura digital ha operado ha sido la reformulación de la unidad de lectura, que hasta el presente siempre fue la misma: el libro. Ciertamente, en la era de la lectura digital, ya no tiene sentido la idea de que leer significa sólo leer libros. Si bien es cierto que esta idea ya fue cuestionada, de algún modo, por la aparición de la prensa y el relato breve, dicho convencimiento sigue dominando, como quizás muestra el hecho de que los relatos deban presentarse siempre bajo la forma de libro de relatos y muchos periodistas publiquen antologías de sus artíctulos y columnas. En efecto, la lectura digital ha supuesto una enorme ampliación de los modos de lectura. Este es un hecho que debemos tener en cuenta a la hora de valorar las repercusiones de la revolución digital. Según García Canclini, los analistas de la lectura se equivocan al subestimar las formas de lectura y escritura no relacionadas con los libros - o con su lectura completa-, para definir al lector como «aquel que lee, entero o en partes, por lo menos un libro en los útimos tres meses», cuando, en realidad, hay «discontinuas, pero frecuentes, prácticas de lectura efectuadas en computadoras y celulares» $(2015 \mathrm{a}: 23)^{12}$.

Cabe añadir que esta reformulación de la unidad de lectura no sólo afecta al formato, sino también a nuestra idea de calidad. Del mismo modo que nunca hablamos tanto sobre la salud como cuando estamos enfermos, la defensa del canon realizada por un autor como Harold Bloom parece ser indicio de que éste se está viendo alterado de una forma radical, no sólo por las diversas ramas de los estudios culturales, sino también por la aparición de la lectura digital. Poco a poco, la lectura está pasando de ser sólo lectura de libros canónicos -Balzac, Borges o Platón- para pasar a incluir muchos otros tipos de lectura, de calidad indeterminada y, en ocasiones, indeterminable. Al fin y al cabo, tal y como estudia David Casacuberta, en Creación colectiva. En internet el creador es el público (2003), en el mundo digital, la autoría individual se está viendo progresivamente erosionada, dando lugar a un nuevo paradigma en el que no siempre es fácil orientarse, tanto en lo que respecta al sentido -para qué, para quién escribir-, como a la calidad de la literatura -¿es esto que estoy leyendo un futuro clásico que no soy capaz de apreciar?-. Por lo menos, desde este punto de vista, la lectura no ha decrecido, sino, antes bien, ha aumentado, suponiendo incluso una alfabetización de poblaciones que, en su deseo de manejar ordenadores y teléfonos inteligentes, se han visto estimulados a aprender a leer.

También el mismo acto de leer se ha visto modificado. Es significativo que se haya hecho habitual la distinción entre lectura intensiva -textual, lineal, integral y profunda- y lectura extensiva hipermedial, hipertextual, fragmentaria y superficial-. Cabe señalar que no sólo el soporte, sino también el exceso de información, ha generado - por ejemplo, en el mundo académico- la aparición y el reconocimiento de nuevos modos de lectura, como el scanning o escaneo - un tipo de lectura salteada que busca, con la mirada o con un buscador, algún tema específico- o el skimming u hojeada -un tipo de lectura que tiene como objetivo hacerse una idea general del texto, generalmente un artículo

12 Véase también Hacia una antropología de los lectores (2015b), de García Canclini. 
académico, y de su pertinencia para la propia investigación- ${ }^{13}$. Ciertamente, este tipo de lecturas salteadas y «en túnel» ya existían antes de la era digital, si bien cabe pensar que ésta las ha hecho más frecuentes y necesarias.

Fuera del ámbito académico también era habitual, antes del advenimiento de la era digital, una lectura superficial y fragmentaria. Tal ha sido el caso, desde el siglo XIX, de la lectura de los periódicos, cuya lectura es salteada y en diagonal. No olvidemos, por otra parte, que ya antes existieron géneros como el almanaque, y que, en definitiva, los libros sagrados no fueron escritos para ser leídos íntegramente, sino para ser explorados y comentados. Quizás sólo la narrativa extensa exige una lectura reposada, lineal e íntegra, más asociada, por el momento, con el soporte papel.

En todo caso, gran parte de las apreciaciones sobre esta cuestión se basan en ideas apriorísticas $\mathrm{y}$, en ocasiones, sentimentales, pues lo cierto es que los estudios no pueden ser concluyentes, ya que el cambio es relativamente reciente y, además, no existen todavía personas cuya vivencia de la lectura haya sido exclusivamente digital.

Los últimos avances en tinta electrónica y en nuevas técnicas de retroiluminación están haciendo que pierda fuerza el argumento de la fatiga o la alteración ocular por la excesiva exposición a las pantallas, hasta el punto de ser considerado un problema menor frente al conjunto de malos hábitos de lectura anteriores, como son las malas posiciones, la iluminación insuficiente, la distancia incorrecta respecto del papel, la lectura ininterrumpida o el tamaño excesivamente reducido de la letra. Lo cierto es que algunos de estos aspectos, fundamentalmente el del tamaño de la letra, ha sido bastante bien resuelto en el ámbito de la lectura digital, donde se puede ampliar la letra sin temer gastos en papel o maquetado.

Con todo, Anne Mangen, una de las principales figuras en el análisis de los hábitos de lectura, de la Universidad Noruega de Stavanger, realizó, en 2014, un experimento que parece apuntar al hecho de que la lectura en ebook implica un cierto déficit de comprensión. El experimento mostraba que un grupo de cincuenta personas que habían leído en ebook una historia de misterio recordaban significativamente peor los detalles de la trama que otro grupo de cincuenta personas que habían leído el mismo relato en formato de libro impreso. Una de las explicaciones podría ser, según Mangen, que la retroalimentación táctil o áptica del libro electrónico es inferior a la del libro de papel a la hora de apoyar la reconstrucción mental de una historia. De algún modo, al leer un libro de papel, sentimos que la pila de páginas de la izquierda crece y la de la derecha decrece, y esto supondría, de modo inconsciente, una ayuda, tanto en lo que respecta a la comprensión, como en lo que respecta a la memorización. Pero antes de pasar a realizar una valoración general de la lectura y la escritura en el nuevo paradigma digital, analizaremos los nuevos hábitos lectores en el ámbito de la ciberliteratura.

\footnotetext{
13 Puede encontrarse una buena síntesis de estos modos de lectura en «Types of Reading», de Maija MacLeod, en http://fis.ucalgary.ca/Brian/611/readingtype.html (última consulta, 7-10-2018).
} 


\section{2. Ciberlectura}

Veamos, a continuación, en qué consiste ese nuevo modo de leer que hemos dado en distinguir con el término «ciberlectura». No se trata, claro está, de multiplicar los términos, sino, simplemente, de asumir que, a diferencia de la mera lectura en soporte digital, la aparición de la ciberlectura ha supuesto una verdadera revolución de la idea tradicional de lectura, en virtud de las posibilidades que encierra la conexión a internet, el uso del hipertexto, la hipermedialidad y la interacción colaborativa entre la obra y el lector. Se trata de una mutación de la propia naturaleza de la lectura, que ha llevado a un autor como Patricio Pron a preguntarse si realmente «ipodemos seguir llamando «leer» a una actividad que tiene tanto de lectura como de interpretación de imágenes y mapas, resolución de acertijos y visionado de fragmentos audiovisuales?» (Pron, 26/03/2016)

Pero antes de pasar a analizar los principales cambios que han dado lugar a la ciberlectura, debemos relativizar su aparente novedad, con la finalidad de ganar en objetividad y atemperar nuestro juicio. Recordemos, con García-Canclini, que «los saberes y los imaginarios contemporáneos no se organizan, desde hace al menos medio siglo, en torno de un eje letrado, ni el libro es el único foco ordenador del conocimiento» (2015b: 4). Más aún, la crisis del libro como fundamento del saber y la cultura se remonta, como mínimo, al siglo XVII, cuando el paradigma científico empieza a imponerse sobre el humanístico14. Se da, pues, la paradoja, de que el inicio de la decadencia del libro coincide con la aparición de la imprenta, que, a pesar de multiplicar su presencia, no va a lograr detener el proceso que lo va a convertir en objeto de arte, soporte del ocio o mera mercancía, frente a la ciencias duras y las «ciencias del espíritu», que se expresarán progresivamente bajo la forma del artículo, totalmente hegemónica en nuestros días.

Por otra parte, es difícil no coincidir con Virginia Zavala, quien considera que «no hay una manera «esencial» o «natural» de leer y escribir», por la sencilla razón de que «los significados y las prácticas letradas son el producto de la cultura, la historia y los discursos» (cit. en Cassany, 2006: 21). No debemos, pues, apegarnos desesperadamente a las formas conocidas de lectura, simplemente porque son conocidas, sino evaluar cuáles son sus virtudes y carencias. En todo caso, no se trata del primero ni del último cambio de la naturaleza de la lectura, y puede ser balsámico, para aquellos a los que estos cambios producen cierta ansiedad, pensar que en un futuro, aquellos que ya se hayan acostumbrado a este nuevo modo de leer, experimentarán la misma sensación de amenaza y decadencia ante algún más que probable cambio futuro en la naturaleza de la lectura.

A continuación, intentaremos presentar las características principales de la ciberlectura, dejando para el siguiente apartado las valoraciones negativas y positivas que han merecido por parte de estudiosos, filósofos, escritores y público en general:

1. Hipertextualidad: Como ya vimos en el apartado 1, una diferencia fundamental de la ciberlectura, respecto de la lectura tradicional, es su carácter no lineal, posibilitado por la técnica del hipertexto. Mediante un sistema de enlaces, el lector puede «saltar»o «navegar» de una parte a otra

\footnotetext{
${ }^{14}$ Es fundamental para reconstruir este proceso un libro como Cosmópolis. El trasfondo de la modernidad (2001), de Stephen Toulmin.
} 
del texto primario que está leyendo, y, en ocasiones, a las de otros textos secundarios, con las que el texto primario puede estar conectado. Este tipo de saltos tiene toda una serie de virtualidades positivas -apertura, ampliación, coparticipación, libertad- y negativas -dispersión, distracción, ansiedad, olvido-, que, poco a poco, autores, editores y lectores exploran y evalúan. En todo caso, la hipertextualidad siempre es opcional, ya que el lector suele tener la potestad de decidir si quiere utilizar o no los enlaces.

2. Supratextualidad: Otra característica fundamental de la ciberlectura es la supratextualidad, esto es, la superación de lo textual -letras, palabras, frases- como referencia principal de la lectura, en virtud de la incorporación de otro tipo de unidades de lectura no textuales o supratextuales. De este modo, «leer ya no es sólo entender palabras y frases», sino también «saber usar iconos de navegación, barras de desplazamiento, pestañas, menús, hipervínculos, funciones de búsquedas de texto, imágenes y músicas, mapas de sitios» (García Canclini, 2015: 27).

3. Fragmentariedad: La no linealidad no implica sólo una lectura salteada, en términos de hipertextualidad, sino también una lectura parcial. Según un estudio de la empresa ClickTale, que analizó durante dos meses el comportamiento de un millón de cibernautas, la mayoría de los usuarios no leen nunca una página web entera, sino que apenas se detienen a leer las que visitan entre 19 y 27 segundos ${ }^{15}$. Por su parte, el Dr. Jakob Nielsen, director del Nielsen Norman Group, probó, mediante un estudio de seguimiento ocular, que los cibernautas leen menos del $20 \%$ del contenido de las páginas web que consultan. Dicha lectura, además, no sigue un patrón lineal, sino que dibuja con los ojos una «F»-por ello la llama «lectura en $\mathrm{F} »-$, ya que leen las primeras líneas, luego escanean las siguientes por la parte izquierda, se detienen de nuevo en el centro y vuelven a descender por la margen inferior izquierda (Nielsen, 2006: html). Como era de esperar, el hecho de que muchos pasen más tiempo frente a pantallas que frente a libros en papel o, incluso, ebooks, ha supuesto, según Ziming Liu, profesor de Bibliotecomonía de la Universidad Estatal de San José, que la lectura en papel haya incorporado patrones típicos de la lectura en pantalla, como es la lectura fragmentaria, no lineal, aleatoria o en «escaner»o «en túnel», esto es, basada en la búsqueda de palabras clave.

4. Participación: La ciberlectura se caracteriza también por su carácter participativo. Para empezar, cualquier texto, impreso o digital, acepta un cierto grado de participación por parte del lector, quien completa con sus ideas y referencias el significado del texto que lee. Estudiar este tipo de participación fue el objetivo de la llamada «estética de la recepción», cuyos principales integrantes fueron Hans Robert Jauss o Wolfgang Iser, a los que se sumará Umberto Eco con su Obra abierta, de 1962. Evidentemente, la ciberlectura lleva más allá las posibilidades de interacción entre la obra y el lector, que pasará a transformarse en lectoautor. Este tipo de participación suele adoptar, por lo menos, tres formas básicas: la reordenación constante del texto en virtud de su carácter hipertextual ${ }^{16}$; la

\footnotetext{
${ }^{15}$ Cf. «Puzzling Web Habits across the Globe», Blog ClickTale, 31 de Julio de 2008, en https://www.clicktale.com/ academy/blog/puzzling-web-habits-across-the-globe-part-1/ (última consulta, 7-10-2018).

${ }^{16} \ll$ El hipertexto requiere la participación activa del lector, para poder accionar estos enlaces que lo convierten justamente en un texto nuevo, abierto, heterogéneo. Más allá de la alteración de la lectura secuencial, la clave del fenómeno radica en
} 
edición, parcial o total, del texto, mediante algún tipo de editor de textos de tipo wiki; la incidencia en la obra que se lee, o en las futuras obras del autor, mediante la publicación de comentarios abiertos o privados acerca de la obra, que puede condicionar, a su vez, la lectura de los siguientes lectores. De este modo, el lector implícito, que es ese ser impreciso al que se dirige imaginariamente el escritor cuando escribe, y que tiene una enorme influencia en su modo de escribir, ha dejado de ser impreciso y homogéneo -Balzac, por ejemplo, escribía pensando en un público francés, burgués y monocultural, para pasar a ser más presente y heterogéneo, pues el lector ha pasado a tener una voz directa y, al mismo tiempo, más global, interclasista y multicultural. No cabe duda de que el impacto del lector implícito en la mente de los escritores va a modificar, a su vez, los modos de escribir y de leer sus obras.

5. Desjerarquización: La ciberlectura ha supuesto una profunda crisis del criterio lector, causada, entre otros factores, por la crisis del libro como unidad lectora, el desdibujamiento de la autoridad, la hiperabundancia de textos, y el desdibujamiento del canon. En primer lugar, tal y como señalamos más arriba, uno de los efectos principales de la lectura en soporte digital es la crisis de la noción de libro en tanto que unidad de lectura, pues esta ha pasado a adquirir una existencia más intangible, imprecisa, inabarcable y fragmentaria. En segundo lugar, la ciberliteratura ha supuesto un cierto desdibujamiento de la autoridad, tanto en lo que respecta a la autoridad creativa, que ahora es pública y participativa, antes que individual y profesionalizada, como en lo que respecta a la autoridad cognoscitiva, que se ha visto repartida entre millones de blogs, webs, comentarios o usuarios de redes sociales. En tercer lugar, la hiperabundancia de los textos - que ya no son exclusivamente libros- o, al menos, el aumento exponencial de la sensación de disponibilidad de los textos, ha redundado en un aumento de la ansiedad creadora, lectora y, también, evaluadora. Ciertamente, los tres procesos aquí descritos han provocado una crisis del criterio a la hora de evaluar la calidad de las «obras» y un desdibujamiento del canon literario. Recordemos, con Harold Bloom, que el término «canon»etimológicamente, 'caña' o 'vara de medir' y, por extensión, 'norma'- designa un conjunto orgánico de libros que deberían ser leídos, por su valor literario o filosófico, y de los cuales puede abstraerse una serie de reglas o principios de cómo escribir o pensar. A su vez, el canon literario -que puede ser genérico, nacional, occidental, oriental o mundial- posee una dinámica en virtud de la cual algunos nombres son incorporados o expulsados de la lista, que no puede exceder el número de libros que puede leerse en el lapso de una vida ${ }^{17}$. La crisis del criterio de valoración literaria ha supuesto un cierto desdibujamiento del canon, que se ha vuelto más fluido, dinámico e inestable. Teniendo en cuenta que todo canon literario es, a su vez, la cifra de una serie de reglas de escritura, pensamiento y lectura, es de esperar que la redefinición del canon tenga, a su vez, efectos en nuestros modos de escribir y de leer.

\footnotetext{
la posibilidad que tiene el lector de realizar determinadas acciones y elecciones tradicionalmente reservadas a los autores y editores de los textos» (Barberoglio, 2013: 104).

${ }^{17}$ Además de El canon occidental de Harold Bloom (1994), puede leerse una buena presentación de la noción de canon en Harold Bloom y el canon literario (2003), de Carlos Gamerro.
} 
6. Evanescencia: Nunca es posible leer dos veces el mismo libro, porque, como diría Heráclito, somos y no somos el mismo lector. Con todo, la ciberliteratura, en virtud de la hipertextualidad, la supratextualidad, la fragmentariedad y la participación, ha ahondado esta imposibilidad haciendo que tampoco sea el mismo el libro al que regresamos, porque no siempre es posible recorrer los mismos saltos hipertextuales, porque las obras pueden haber cambiado en virtud de los cambios que los lectores o el autor hayan realizado, porque no siempre vamos a abandonar las obras en el mismo punto o porque, simplemente, dicho tex to ya no está disponible en la red. Tal y como hemos podido comprobar durante la realización de este ensayo, muchas obras de ciberliteratura-blogonovelas, webnovelas, wikinovelas, ciberpoemas, etc.- no son recuperables al cabo de un cierto tiempo. Todo esto ha llevado a Alayón Gómez a hablar de una «crisis del lector», porque la ciberliteratura «supone la evanescencia del texto literario, algo que hace precaria y fragmentaria la relación del lector con el autor» (2009: html). Ciertamente, la dificultad, en ocasiones la imposibilidad, de releer, por no decir de subrayar, de marcar o de anotar, puede llegar a suponer un cambio muy importante en los hábitos de lectoescritura.

\section{Valoraciones}

En el apartado anterior intentamos describir de forma objetiva, evitando en la medida de lo posible todo juicio de valor, algunas de las características básicas tanto de la lectura en soporte digital como de la ciberlectura. A continuación vamos a tratar de recoger y sistematizar las principales valoraciones de las que ha sido objeto la cibercultura, en general, y la ciberliteratura, en particular. Distinguimos entre valoraciones negativas y valoraciones positivas, y, dentro de cada uno de estos tipos de valoraciones, entre valoraciones cuantitativas y cualitativas. Estas distinciones son analíticas y expositivas, pues somos conscientes de que lo más habitual es que ambos tipos de valoraciones se combinen, de forma fluida e inextricable, en una misma valoración global del fenómeno.

\section{1. Valoraciones negativas}

\section{1. 1. Cuantitativas}

1. Exceso: La enorme disponibilidad de lecturas posibles, ampliada exponencialmente por la conexión a la red, ha supuesto necesariamente ciertos cambios en los modos de leer y escribir. Para empezar, un momento esencial de la lectura es el de la elección de lo que se va a leer, y, como es sabido, a mayor cantidad de opciones, menor seguridad de elección. Sucede, pues, que toda lectura queda tocada por una sensación de inseguridad cognoscitiva, que no puede ser desatendida, pues aunque la lectura literaria tenga un componente lúdico, no deja de implicar siempre algún tipo de juicio de valor. Dice el filósofo Byung Chul Han al respecto que, «con frecuencia, un menos de saber e información produce un más» y que «la negatividad de dejar y olvidar tiene no pocas veces un efecto productivo» (Han, 2013: 17). Ya Alvin Tofller, en su libro El shock del futuro (1970), habló de sobrecarga informativa (information overload), a la que también puede llamarse «infoxicación» o «infobesidad», para referirse al exceso de información en un sistema, en este caso, en el sistema 
formado por la interacción de la persona y el mundo literario. La sobrecarga informativa tiene como efecto, en el lector, un aumento exponencial de la ansiedad lectora -ya existente, por otra parte, en tiempos de Platón, quien se quejaba de no poder leer todos los libros que se escribían-, lo que puede llevar, a su vez, a un bloqueo de la lectura, con el objetivo de evitar la angustia de no poder leerlo todo. La ansiedad lectora también puede llevarnos a leer de forma fragmentaria; a sobreleer de forma superficial y precipitada, renunciando a la la posibilidad de subrayar, releer o meditar; o a escoger preferentemente obras breves, para sentir que se avanza más rápidamente ${ }^{18}$. Por otra parte, el exceso de textos y de información, puede bloquear a los escritores, que podrían sentir que todo está escrito, que no existe un lugar para sus obras o que no tiene sentido ahondar en lo inabarcable.

2. Hiperestimulación: Tanto el exceso de información, como el «ruido» que provocan los enlaces, imágenes o paratextos, implican una cierta hiperestimulación del lector, que puede tener efectos negativos sobre su capacidad de concentración, así como sobre el placer que puede llegar a experimentar al leer un texto. En diversos libros de su serie «líquida» (Modernidad líquida, Amor líquido, Vidas líquidas, etc.), Bauman nos avisa de los peligros del aumento exponencial de las potencialidades (laborales, existenciales, amorosas o recreativas), que pueden llegar a bloquear en la capacidad de las personas para elegir y comprometerse, por lo que implican de renuncia a todas las demás posibilidades. Algo semejante sucedería con el ciberlector, que suele verse tentado por la infinidad de lecturas que están a un solo click de distancia. Uno de los mayores peligros de la hiperestimulación lectora sería la degradación de la lectura reposada, así como de actitudes necesarias para la experiencia literaria de calidad, como son la mirada contemplativa, la capacidad de asombro o el espíritu lúdico. Véase al respecto un libro como Educar en la realidad (2015), de Catherine L'Ecuyer, donde se rechaza el uso de las nuevas tecnologías en la infancia y la adolescencia, por el peligro de que la sobreestimulación apague el asombro, que es el principal motor del aprendizaje.

3. Evanescencia: Ya señalamos en el apartado anterior que usan de las principales características de la ciberliteratura -también de la lectura digital, en la que los soportes están sometidos a la obsolescencia programada- era la evanescencia de las obras. Para empezar, tal y como expresan con felicidad Umberto Eco y Jean Claude Carrière, en las conversaciones recogidas en Nadie acabará con los libros (2010), «no hay nada más efímero que los soportes duraderos» (27). Basta pensar en todos los soportes que hemos dejado ya atrás - discos de vinilo, casetes, disquetes, cintas Beta y cintas VHS, CD-ROMs, DVDs, USBs, MP3s, MP4s y espacios de almacenamiento en la nube- y en toda la información que hemos perdido en las sucesivas migraciones informáticas. Jean-Claude Carrière pone como ejemplo el caso de cierto cineasta belga que «conserva en su trastero dieciocho ordenadores, simplemente para poder ver trabajos antiguos» (Eco y Carrière, 2010: 29). Algo semejante sucede con muchos de los contenidos que se van publicando en internet, donde millones de blogs, webs y cuentas de redes sociales hibernan durante meses para luego ser abandonadas y, finalmente, borradas. Son infinitos los ciber-icebergs que vagan por la red, ya sean cuentas de facebook o de twitter de personas

\footnotetext{
${ }^{18}$ Sobre la sobreabundancia informativa y la crisis del criterio de selección, véase El conocimiento inútil (2007 [1988]), de Jean-François Revel.
} 
difuntas, webs de empresas que quebraron hace años o blogs abandonados a las pocas entradas. Como indicamos más arriba, durante el proceso de redacción de este informe, nos hemos encontrado con numerosas obras que habían desaparecido de la web. Así, en la página Literatura electrónica hispánica, albergada en la Biblioteca Cervantes Virtual, sólo funcionaban tres enlaces de los nueve que incluía el apartado dedicado a las novelas hipermedia, y sólo uno de los tres enlaces del apartado dedicado a las blognovelas. En algunas ocasiones, hemos podido recuperar dichas obras por otros caminos, pero en muchas otras ocasiones, no las hemos podido consultar. Por otra parte, no es imposible que, con el tiempo, suceda alguna contingencia, como una guerra, un virus o un desastre climático, que destruya algunos de los servidores en los que se almacena buena parte de esa información. Finalmente, tampoco es seguro que en el futuro dispongamos de la energía suficiente para hacer que funcionen todas esas máquinas. En ese caso, dicen Eco y Carrière, «podremos seguir leyendo libros, durante el día, o por la noche con una vela, cuando toda la herencia audiovisual haya desaparecido» (2010: 35). Quizás no es casual que, en numerosas películas y novelas de imaginario postapocalíptico, desde Fahrenheit 451 (1953) hasta El libro de Eli (2010), el libro impreso cumpla una función simbólica muy importante ${ }^{19}$.

\section{1. 2. Cualitativas}

1. Crisis del criterio de calidad literaria: Antes de hablar de la crisis de la calidad literaria, que habría supuesto, según sus detractores, el advenimiento de las literatura digitales, debemos hablar de la crisis del criterio de valoración de la calidad literaria. Como indicamos en el apartado anterior, la literatura en soporte digital y la ciberliteratura estarían relacionadas con toda una serie de procesos que entorpecen, objetiva o subjetivamente, nuestras capacidades para distinguir entre buena y mala literatura. Evidentemente, la crisis del criterio literario es anterior a la aparición de la literatura digital, como probaría, por ejemplo, la redefinición del canon propuesta por los estudios culturales, ya en los años 80, o la atención que autores como Jorge Luis Borges o Walter Benjamin prestaron a subgéneros populares, como la literatura policial, la milonga o los dibujos animados. Este proceso, conectado con crisis filosóficas más profundas, como, por ejemplo, el giro lingüístico o el pensamiento débil posmoderno, se ha visto ahondado por la llegada del mundo digital. Ciertamente, «la difusión de multitud de opiniones consideradas entre iguales a través de la red sitúa en una esfera de legitimación debilitada potencialmente a los críticos y reseñistas en lo que en ocasiones se percibe como una ausencia de filtro» (Escandell, 2014: 66).

2. Crisis de la calidad literaria: Los escépticos de la ciberliteratura consideran que su advenimiento ha supuesto una degradación de la calidad literaria debido, por lo menos, a cuatro procesos.

\footnotetext{
${ }^{19}$ Sobre el futuro del libro, véase Chartier y Rodríguez de las Heras (2001: 11-42).
} 
2. 1. Igualación cultural y cualitativa de la literatura: En primer lugar, los diferentes cánones literarios tienden a confluir en una sola cultura de masas, cortada según el patrón de la cultura de masas americana. Este proceso, al que Ulrick Beck llamó «cosmopolitismo banal», George Ritzer, «McDonaldization» y Hamelinck, «sincronización cultural», apunta al impacto que el consumo global ha tenido en la vida cotidiana de casi todos los pueblos del planeta, si bien puede ser estudiado de forma particularizada en los nuevos modos de escribir y leer literatura. La nueva escritura buscaría la intertraducibilidad, evitando, por ejemplo, el verso, el juego linguí́stico o las referencias demasiado específicas a una cultura particular; el imaginario se llena de referencias a la cultura global de masas -mitología cinematográfica, musical, marcas comerciales, universo informático, medios de comunicación y transporte-; su forma de narrar adopta técnicas cinematográficas, televisivas y, ahora, digitales; y se niega, en general, la distinción entre alta y baja literatura ${ }^{20}$. Este proceso, por supuesto, se había visto acelerado y ahondado por la revolución digital.

2. 2. Falta de profundidad estética: En segundo lugar, en su nueva vida digital, la escritura y la lectura han experimentado una aceleración que no les permite una verdadera profundidad estética. Según Bauman, la aceleración digital no es la enfermedad, sino el síntoma de la verdadera aceleración, científica, financiera y existencial, que ha supuesto una pérdida de sentido o un vértigo de lo efímero, que tratamos de acallar, a su vez, mediante una aceleración mayor. Este círculo vicioso entre la crisis del sentido y la velocidad se halla felizmente expresado en una cita de Thoreau a la que Bauman recurre habitualmente: «Cuando se patina sobre hielo quebradizo, sólo la velocidad puede salvarte». En todo caso, como señalamos anteriormente, la aceleración impediría algunos de los modos básicos de la sensibilidad literaria, como son la observación, la meditación o el asombro. Según Byung Chul Han, el «me gusta» de Facebook, que representa un «juicio de gusto» para el que no se requiere ninguna contemplación que se demore, es el paradigma de cómo «la hipercomunicación anestésica reduce la complejidad para acelerarse» (Han, 2013: 31-32). Otro modo de aceleración, que apareció ya con la invención de la máquina de escribir, estaría relacionado con el hecho de que las letras de molde puedan otorgar a nuestros borradores el prestigio de un texto ya acabado o publicado, hecho que podría suponer un bloqueo de nuestras capacidades críticas (Eco y Carrière, 2010: 105-106).

2. 3. Crisis de la narratividad: En tercer lugar, los críticos de la ciberliteratura consideran que la fragmentariedad de la escritura y la lectura, de las que ya hablamos en el apartado anterior, han supuesto una crisis, tanto de la narratividad literaria, como de la lectura atenta y profunda. De un lado, la crisis de la narratividad histórica, política y existencial hunde sus raíces en las filosofías de la sospecha (Freud, Marx, Nietzsche), en la literatura de vanguardia (Proust, Joyce, Faulkner) y en la crisis posmoderna de los grandes relatos (Lyotard), para ahondarse en las últimas décadas del siglo XX y primeras del XXI. Según Han, este tipo de dispersión o discronía temporal «hace que el tiempo transcurra sibilante sin dirección y se descomponga en una mera sucesión de presentes temporales, atomizados», con lo cual «el tiempo se hace aditivo y queda vacío de toda narratividad» (2013: 65). Como no podía ser de otra forma, la literatura se ha ido impregnando de esta falta de narratividad,

${ }^{20}$ Véase al respecto Castany Prado, 2007: 315-319 
intensificada por la dispersión y sobreabundancia de hechos y contenidos digitales, imposibles de engarzar en una historia coherente y omniabarcadora. De este modo, la literatura habría perdido una de sus funciones primordiales, como es hacer de la facticidad caótica y amorfa que compone el mundo una historia con sentido. A esta incapacidad para narrar y dotar de significar al mundo, se le añadiría una lectura superficial y fragmentaria, que sería incapaz de completar lo que la obra que lee no ha sido capaz de ofrecerle. Para muchos, está suponiendo una degradación de la lectura literaria, y, en virtud de la importancia del lector para completar todo texto, una degradación de la literatura misma.

2. 4. Mercantilización de la obra y el autor: Los críticos de la cibercultura también consideran que ésta ha catalizado el proceso de mercantilización posindustrial de la literatura. De algún modo, el mundo digital habría obligado al autor a convertirse en una especie de promotor o community managers de sus propias obras, restándole tiempo y energías de su tarea creadora. Según García Canclini, «el objeto literario es, más que las obras o el acto inapresable de la creación, el proceso sociocultural de su elaboración, su tráfico y las modulaciones en que se altera su sentido» (2015: 79). Ciertamente, desde Jauss o Iser, sabemos que el objeto literario es tanto la obra como las relaciones entre obras, intermediarios y lectores. Pero, como decíamos, el autor corre el peligro de convertirse en el gestor de un producto literario, presentado como algo acabado y perfecto, en vez de centrarse en un proceso autónomo y progresivo de búsqueda estética y filosófica. Si eso sucediese, entonces sí tendría sentido hablar de la «muerte del autor».

3. Crisis del aura o el valor cultual del libro: Los críticos de la cibercultura no sólo deploran la crisis del libro en tanto que unidad lectora, sino también su pérdida de aura o valor cultual. Ya Walter Benjamin, en su ensayo «La obra de arte en la era de su reproducción técnica», publicado en 1936, estableció que el «valor de culto» o «valor cultual» de un objeto sagrado reside en su existencia y no en su exposición. Tanto es así que su inaccesibilidad, su secreto, más que su accesibilidad, lo que lo dota de valor cultual. El problema residiría en que, en la era de la reproducción técnica de la cultura, más aún en la era de internet, la sobreexposición de las obras de arte, y en nuestro caso de las obras literarias, haría desaparecer por completo el aura, porque «todo lo propio de la autenticidad no puede ser reproducido, ya sea tecnológicamente o de otro modo» (Benjamin, 1936: 14) ${ }^{21}$. Otra causa de la pérdida del aura sería la imposibilidad de fijar los textos de forma filológica, por la sencilla razón de que «el ordenador no elimina las etapas intermedias, sino que, al contrario, las multiplica» (Eco y Carrière, 2010: 104). De este modo, la idea de «texto base» o «texto fijado», que era una de las principales herencias que la filología humanística había recibido de la filología bíblica, desaparecería, despojando a los libros del último halo de aura sagrada que todavía poseían. No es extraño, pues, que muchos lamenten la desacralización del objeto libro, que, frente al minimalismo y pulcritud de los

\footnotetext{
${ }^{21}$ Incluso lo que muchos consideran el último elemento sagrado, que es el rostro -véanse las teorías de Emmanuel Lévinas, que ve en el rostro el lugar donde se nos aparece la trascendencia del otro- se está viendo amenazado por la sobreexposición cibernética. «El «rostro humano» con su valor cultual hace tiempo que ha desaparecido de la fotografía. La época de Facebook y Photoshop hace del «rostro humano» una faz que se disuelve por entero en su valor de exposición. La faz (face) es el rostro expuesto sin «aura de la mirada» (Han, 2013: 27). Véase también Baudrillard (1983: 28).
} 
ebooks, las tablets y los smartphones, ha pasado a ser visto como un trasto que acumula polvo y ocupa espacio. Todo ello ha generado una cierta nostalgia del libro, que se expresa en numerosas apologías del libro de papel, como Tocar los libros (2010), de Jesús Marchamalo o Nadie acabará con los libros (2010), de Umberto Eco y Jean-Claude Carrière.

4. Crisis del pensamiento: Ciertamente, la neuroplasticidad del cerebro, en virtud de la cual el tipo de actividad mental que desarrollamos puede llegar a reconfigurar nuestro cerebro, ha supuesto una cierta interiorización cognitiva de las técnicas que han ido inventándose a lo largo de la historia. Desde este punto de vista, no nos hallaríamos más que ante una nueva mutación entre las muchas que ha experimentado, y seguirá experimentando, nuestro cerebro. Sin embargo, desde Darwin sabemos que no toda mutación prospera en evolución, de modo que cabe preguntarse si la mutación digital es positiva o, como sugería, ya en 1997, Giovanni Sartori, en Homo videns. La sociedad teledirigida, supone un peligro tanto para el pensamiento como para la vida. En todo caso, los detractores del mundo digital consideran que la cibercultura, en general, y la ciberliteratura, en particular, han supuesto una degradación del pensamiento, al menos en cuatro aspectos:

4. 1. Crisis de la abstracción: Según afirma Nicholas Carr, en su libro Superficiales. ¿Qué está haciendo Internet con nuestras mentes? (2011), «las herramientas de la mente amplifican y a la vez adormecen las más íntimas y humanas de nuestras capacidades naturales: las de la razón, la percepción, la memoria, la emoción» (250), llegando a sugerir que la hiperestimulación y la aceleración que implica el uso de internet podría incluso provocar una reducción de la empatía y, por lo tanto, una cierta degradación moral (266). Por su parte, Patricia Greenfield, profesora de psicología en la Universidad de UCLA, tras repasar medio centenar de estudios sobre los efectos de los medios de comunicación en las capacidades cognitivas, concluyó que el uso de Internet está debilitando nuestras capacidades para el «pensamiento profundo», que permite «la adquisición consciente del conocimiento, el análisis inductivo, el pensamiento crítico, la imaginación y la reflexión».

4. 2. Crisis de la introspección: Según los detractores de la cibercultura, la introspección es un acto que está desapareciendo por culpa de las innovaciones tecnológicas. Según Hargreaves, «enfrentándose a momentos de soledad en sus coches, en la calle o en las cajas de los supermercados, cada vez hay más gente que no recupera el dominio de sí mismo, sino que escudriña en los mensajes de sus teléfonos móviles en busca de la más mínima evidencia de que alguien, en alguna parte, puede necesitarles o quererles» (Hargreaves, 2003: 25, cit. en Bauman, 2005: 60). Por su parte, el prestigioso sociólogo alemán Hartmut Rosa, en su último libro Social acceleration: a new theory of modernity (2015), considera que no tenemos tiempo de «apropiarnos» del mundo que nos rodea, ni de reflexionar, interpretar, observar o entrar en conversaciones profundas. Con todo, Rosa no cree que sea la tecnología la que nos lo impide, sino el modo en como vivimos la tecnología en el seno de la sociedad del capitalismo tardío. Sea como sea, la crisis de la introspección, que es una de las principales virtudes de la literatura, conlleva, a su vez, una crisis de la escritura y la lectura. 
4. 3. Crisis de la contemplación: Ya señalamos más arriba que uno de los principales peligros de la hiperestimulación y la aceleración -laboral, existencial o lectora- es la degradación de actitudes necesarias para una vivencia -laboral, existencial o lectora- de calidad, como son la mirada contemplativa, la capacidad de asombro o el espíritu lúdico. Según Umberto Eco, «la velocidad con la que la tecnología se renueva nos obliga a un ritmo insostenible de reorganización permanente de nuestras costumbres mentales [...]. Y cada nueva tecnología implica la adquisición de un nuevo sistema de reflejos, que requiere nuevos esfuerzos, y todo ello en términos de tiempo cada vez más breves» (Eco y Carrière, 2010: 45). La ansiedad que este reciclaje permanente nos provocaría bloquearía un pensamiento profundo y atento, lo cual supondría, a su vez, la desecación de uno de los principales afluentes de la creación literaria.

4. 4. Crisis de la memoria: Numerosos estudios apuntan a que el cerebro tiende a economizar esfuerzo mediante la deslocalización de la memoria en todo tipo de aparatos y soportes. De este modo, el hecho de saber que las capitales del mundo o los rasgos fundamentales del surrealismo son fácilmente consultables en nuestros smartphones, el cerebro no realizaría el esfuerzo de retener ese tipo de información. Esta dejación de la memoria tendría, a la larga, importantes efectos cognoscitivos y literarios. Recordemos, por ejemplo, cómo, para Proust, «el «disfrute inmediato» no es capaz de lo bello», pues «la belleza de una cosa «solo aparece mucho más tarde» a la luz de otra como reminiscencia» (Han, 2013: 65). Por otra parte, el mero almacenamiento de datos no permite que éstos se impregnen de nuestra propia existencia ni se articulen en una narrativa propia. Es en este sentido que, en nuestros días, la memoria se nos aparece como un montón de residuos y de datos, como un almacén o depósito en el que las cosas «se limitan a yacer unas junto a otras, no están estratificadas. Por eso le falta la historia» (Han, 2013: 64).

5. Peligros éticos y políticos: Para los escépticos de la cibercultura, la degradación de la calidad del pensamiento y la literatura tiene consecuencias éticas y políticas negativas, que en muchos casos supondrían un grave peligro. Algunos de estos efectos ético-políticos ligados a la decadencia de la lectura en el seno de la cultura digital serían (5.1) la crisis de la democracia, (5.2) la crisis de la empatía, (5.3) la cibermanipulación de la información o (5.4) el imperativo de la conexión y la disponibilidad.

5. 1. Crisis de la democracia: La idea de que la democracia depende de la formación, en general, y de la capacidad lectora, en particular, de los ciudadanos, hunde sus raíces en el humanismo renacentista y en los movimientos de reforma religiosa, que defendían una lectura individual de la Biblia. Hoy en día se ha generalizado la idea de que la crisis de la lectura, provocada, o catalizada, por la cibercultura, está poniendo en peligro la democracia. Es difícil no estar de acuerdo en que existe una conexión entre formación, lectura y democracia. Es discutible, sin embargo, que sea la cibercultura la que haya provocado esa crisis. Seguramente, con otras políticas culturales y económicas, la cibercultura podría convertirse más en una ayuda que en un problema para la formación de los ciudadanos. Por otra parte, según comenta con agudeza García Canclini, el verdadero peligro para la democracia no es tanto lo no leído como lo ilegible: «los folletos publicitarios de agotadores párrafos, 
los contratos en letra diminuta de los bancos, de las tarjetas de crédito, de las hipotecas [...] la composición y las contraindicaciones de medicinas»; lo que le lleva a preguntarse, finalmente, si «¿salvarán la democracia las políticas de promoción de la lectura o las políticas de publicación de lo ilegible?»(García Canclini, 2015: 28). Cabe decir que una de las forma de la ilegibilidad es la sobreabundancia, que ha generalizado el llamado efecto «tablón de anuncios», en virtud del cual noticias o textos importantes pasarían desapercibidos en el flujo constante e inasimilable que recorre nuestras pantallas.

5. 2. Crisis de la empatía: Más grave si cabe es el hecho de que el efecto «tablón de anuncios» puede llegar a erosionar nuestra capacidad de empatía hacia los demás. Recordemos, con Nicholas Carr, que la hiperestimulación y la aceleración que implica el uso de internet puede, incluso, provocar una reducción de la empatía y, por lo tanto, una cierta degradación moral (2011: 266). Por otra parte, según demostraron Comer Kidd y Castano, en el artículo «Reading Literary Fiction Improves Theory of Mind», publicado en la revista Science, el 3 de octubre de 2013, la lectura de literatura de ficción de calidad aumenta la capacidad empática de los lectores y, por lo tanto, su sentimiento moral. Así, pues, la decadencia, no tanto de la lectura -puesto que en términos cuantitativos ésta no parece haberse reducido-, como de la calidad y cualidad de las obras que leemos -que pertenecen a géneros de no ficción (blogs, webs, mensajes, ensayos, artículos) y de baja calidad (escritura y lectura rápida, superficial y poco profunda)- podría estar desecando una de las principales fuentes de educación sentimental y moral, como es la literatura de ficción de calidad.

5. 3. Cibermanipulación de la información: Según García Canclini, no es lo mismo «la avidez de información y el interés por el saber» (2015: 90). También Byung Chul Han considera que «transparencia y verdad no son idénticas», más bien «cuanta más información se pone en marcha, tanto más intrincado se hace el mundo» (2013: 23 y 79). Pero la hiperinformación y la hipercomunicación que caracterizan a la cibercultura no sólo estarían erosionando nuestro acceso -objetivo y subjetivo- a la verdad, sino también favoreciendo la manipulación de la misma, hecho que podría llegar a tener unas graves consecuencias políticas. Según Gayatri Spivak, la globalización es, en buena medida, globalización de datos y metadatos, que, en la mayor parte de las ocasiones, sirve para fines comerciales, políticos y de espionaje. La pregunta subyacente es ¿para qué queremos todos una información que sólo beneficia a unos pocos? Es normal que esté apareciendo una corriente de opinión que, siguiendo las teorías de decrecimiento económico de Serge Latouche (2009 y 2011), proponga un cierto decrecimiento informativo o digital. Véanse, por ejemplo, El conocimiento inútil (2007 [1988]), de Jean-François Revel, o The Slow Professor: Challenging the Culture of Speed in the Academy (2016), de Berg y Seeber.

5. 4. Imperativo de la conexión y la disponibilidad: Otro problema político asociado a la cibercultura es el de la sobreexposición voluntaria de la propia intimidad. Según Innerarity, la conectividad se ha compertido en un imperativo técnico como moral: «Se trata de estar siempre integrado, disponible, accesible. No llevamos bien la desconexión porque estamos psicológicamente configurados con la sensación de que nos estamos perdiendo algo, sin argumentos para frenar la 
multiplicación de los contactos y apremiados por la exigencia de rendimiento continuo» (21-05-2015). Por su parte, Crary considera que las temporalidades sin pausa son corrosivas para el tejido de la vida social y la sociedad civil: «al fomentar una cultura vacía de autopromoción y autoabsorción, las tecnologías 24/7 perpetúan la ilusión de un tiempo sin espera, de una instantaneidad a demanda, de adquirir y tener manteniéndose aislado de la presencia física de otros y de cualquier sentido de la responsabilidad que esta pueda conllevar» (24-05-2015). Poco a poco la sociedad ha ido tomando conciencia de los efectos del exceso de exposición y de interpelación, tales como la «infoxicación», la «nomofobia» (de «no mobile fobia»), la baja autoestima (varios estudios han demostrado que la hiperconciencia física provocada por las selfies o autorretratos está relacionada directamente con el aumento de las operaciones de cirujía estética) o la heteronomía identitaria, consistente en la dependencia de la opinión de los demás para constituir la propia identidad, y el aumento subsiguiente de miedos e inseguridades. Por su parte, en Patologías de la realidad virtual. Cibercultura y ciencia ficción (2015), Teresa López-Pellisa estudia algunas de las principales patologías relacionadas con la cibercultura y la realidad virtual, como la «metástasis de los simulacros» (99-123), «el síndrome del cuerpo fantasma» (124-165) o «el misticismo agudo» (166-191). No es extraño, pues, que en los últimos años hayan ido apareciendo manifiestos y elogios de la desconexión, tales como Social acceleration: a new theory of modernity (2015), de Harmut Rosa; así como aplicaciones que permiten la desconexión, tales como AntiSocial, Afirewall o SelfControl.

\section{2. Valoraciones positivas}

Veamos, a continuación, cuáles son los principales argumentos de los defensores de la cibercultura, en general, y de la ciberliteratura, en particular. Trataremos de presentarlos como respuesta a las críticas presentadas en el apartado anterior, a pesar de que no siempre aparecen engarzados de esta manera.

\section{2. 1. Cuantitativas}

1. Frente al argumento del exceso: Frente a aquellos que critican que la cibercultura ha supuesto un sobreexceso informativo y literario, sus defensores responden con diversos argumentos:

1. 1. Siempre ha existido un exceso de libros y de información: Ya Platón se quejaba de que no podía leer todos los libros que se escribían. Por otra parte, el tema de la extensión y ordenación de las bibliotecas es una metáfora epistemológica muy antigua. En la que puede ser considerada la primera guía de biblioteconomía, intitulada Recomendaciones para formar una biblioteca (1627), Gabriel Naudé se adhiere al escepticismo tras realizar toda una serie de consideraciones acerca de la inabarcabilidad e inclasificabilidad de los textos ${ }^{22}$. Así, pues, la sobrecarga informativa no es exclusiva del soporte digital.

\footnotetext{
22 También Leibniz consideró que la organización de las bibliotecas era una metáfora de la organización misma del saber. Véase también el prefacio de la Encyclopédie de D’Alembert y Diderot y un cuento como «La biblioteca de Babel» de Jorge Luis Borges (cf.: Eco y Carrière, 2010: 243-246). En todo caso, una de las más interesantes obras recientes que se
} 
1. 2. Lo digital es la única vía de acceso al 99,9\% de los contenidos: Tal y como nos informa la revista Science (2011), en la actualidad, la humanidad genera cada 2 días la misma información que nuestra especie tardaba antes en generar casi 5000 años; información que sólo se halla disponible, en un 99,9\%, en formato digital, pues no hay papel suficiente para publicarlo. Desde este punto de vista, aferrarse a la lectura en papel nos impedirá acceder al grueso de los conocimientos generados en nuestra época. Por otra parte, el mundo digital tiene toda una serie de herramientas, como son los motores de búsqueda, de filtro y de síntesis, totalmente necesarios para orientarnos en este océano de conocimientos.

1. 3. Tras la revolución digital se lee más, sólo que de formas diferentes: Los defensores de la cibercultura suelen esgrimir el argumento de que en el nuevo paradigma digital se lee mucho más, sólo que en formatos diferentes. Según García Canclini, «los ingenieros, juristas, técnicos, comerciantes, políticos, periodistas tratan todo el tiempo con información escrita, hacen cáculos, consultan bases de datos, envían correos y redactan informes. Pero no recurren a los libros de historia o geografía para conocer ciertos datos sino a Google o Google Earth» (2015: 26). Debemos evitar, pues, la tentación de «la melancolía de las cifras» en la que suelen caer las encuestas sobre hábitos lectores, donde siempre se define al lector como lector de libros, sin considerar que también es lectura aquella que se realiza en otro tipo de formatos. Cabe decir que, desde un punto de vista meramente cuantitativo, esto es cierto. Más aún, muchos analfabetos funcionales se han visto forzados a aumentar sus competencias lectoescriturales para poder utilizar las nuevas posibilidades de los teléfonos móviles.

1. 4. La ciberlectura no es la única causa de que se compren menos libros: Indudablemente, el libro electrónico e internet han aumentado exponencialmente la sensación de disponibilidad de los libros, hecho que ha redundado en una disminución de la adquisición física de los mismos. Sin embargo, la disponibilidad digital no es la única causa de esta reducción de las bibliotecas físicas personales, sino que existen muchos otros factores, como la crisis económica, la reducción del tamaño de la vivienda, el aumento de la frecuencia de las mudanzas o la desaparición de la convivencia intergeneracional. Todos estos procesos contribuyen, tanto o más que la revolución digital, a una redefinición del lugar -físico y simbólico- del libro en nuestra sociedad.

1. 5. Son compatibles ambos modos de lectura: Ya Marshall McLuhan, en libros como La galaxia Gutenberg (1962) o Comprender los medios de comunicación (1964), evidenció que la historia de la cultura no es la sustitución absoluta de unas tecnologías por otras, sino la coexistencia de todas ellas tras un período de adaptación. Ciertamente, el ser humano siente demasiado placer al ampliar el abanico de sus posibilidades, como para renunciar a cualquiera de esas técnicas. Así, del mismo modo que el cine no acabó con el teatro, ni la televisión con el cine, tampoco existen razones de peso para pensar que la cultura digital va a acabar con la escrita. Ciertamente, la mayor parte de los adultos son capaces de compatibilizar ambos tipos de lectura. Más aún, la ciberliteratura y la lectura en papel no 
sólo pueden convivir, sino también colaborar, tal y como prueba, por ejemplo, la edición online del Finnegans Wake, de James Joyce (http://finwake.com/1024chapter1/1024finn1.htm), cuya lectura es facilitada, y posiblemente rescatada, gracias al hipertexto. Por si esto no fuese suficiente, tanto los defensores de la cultura impresa, como los defensores de la cultura digital, consideran que el libro en papel nunca desaparecerá, por la sencilla razón de que es un invención insuperable desde un punto de vista técnico, igual que la cuchara, el martillo, la rueda o las tijeras. Con todo, existe el miedo de que, aun existiendo el libro de papel, para uso y disfrute de una minoría, la mayor parte de los futuros nativos digitales ya no sean capaces de leerlo, si no se tiene el cuidado de acostumbrarlos a la lectura lineal, integral y reflexiva característica de la lectura en papel.

1. 6. Quizás el libro no es tan necesario: A la pregunta de si es posible expresarse sin saber leer ni escribir, Umberto Eco responderá que «Homero respondería sin ningún género de duda que sí» (Eco y Carrière, 2010). Ya vimos que Platón lamentaba, en el Fedro, la aparición de la escritura. Nostalgia que también practicará José Bergamín, en La decadencia del analfabetismo (1933), donde se pregunta por las formas de conocimiento que poseían los pueblos sin escritura y se cuestiona qué cosas podría habernos hecho perder su aparición. Así, pues, la presencia o la ausencia del libro de papel no parece ser tan esencial como pensamos. El verdadero problema se halla en la falta de un tiempo de calidad que nos permita mirar con atención y pensar con profundidad. Pero esta cuestión tiene raíces políticas, sociales y económicas mucho más profundas.

2. Hiperestimulación: Frente a aquellos que consideran que el mundo digital conlleva una hiperestimulación, que tiene efectos negativos sobre su capacidad de concentración, así como sobre el placer que puede llegarse a experimentar al leer un texto, los defensores de la cibecultura sostienen que se trata de un desajuste inicial, que vendrá seguido por una nueva cultura de la lectura y la información. Umberto Eco, por ejemplo, ha formulado la teoría de la «decimación», según la cual basta con leer un libro de cada diez: «Para los demás, si controlamos la bibliografía y las notas, nos damos cuenta enseguida de si las referencias indicadas son serias o no. Si la obra es interesante, no es necesario leerla, porque seguramente será comentada, citada, criticada en otras obras, incluida la que hemos decidido leer» (Eco y Carrière, 2010: 66). Por su parte, Jean-Claude Carrière, considera que una biblioteca (otra cosa no es internet) recoge los libros que podemos leer, o que podríamos leer, aunque luego no los leamos nunca, como si fuese una especie de bodega, en la que no conviene bebérselo todo. Deberíamos aprender a hacer lo mismo con los libros: apartarlos como botellas en una bodega para dejarlos madurar: «Esto combatiría por lo menos ese «efecto novedad» tan desagradable que nos obliga a leer un libro porque acaba de salir, porque se acaba de publicar. ¿Por qué no guardarse un libro del que se habla y leerlo tres años después?» (Eco y Carrière, 2010: 227) ${ }^{23}$ Según muestra

\footnotetext{
${ }^{23}$ Véase también el cuento «Cómo me deshice de quinientos libros», de Augusto Monterroso, donde el narrador dice de aquellos amigos que aceptaron llevarse algunos de estos libros a sus casas, que eso volúmenes estaban destinados «a ocupar un lugar que restará espacio y oxígeno a los niños, pero que darán a los padres la sensación de ser más sabios e incluso la más falaz e inútil de ser los depositarios de un saber que en todo caso no es sino el repetido testimonio de la ignorancia y la ingenuidad humanas» (88).
} 
Bayard, en Cómo hablar de los libros que no se han leído (2011 [2007]), estamos tan influidos por los libros que no hemos leído, como por aquellos que sí hemos podido leer. A eso mismo apuntaba Borges cuando afirmaba que un clásico es un libro que hemos leído aunque no lo hayamos leído. Todas estas opiniones no son más que ejemplos de cómo la sobreabundancia y la hiperestimulación no pueden ser combatidas mediante la eliminación, sino mediante el ensayo de nuevas actitudes y prácticas que nos permitan filtrar y escoger mejor.

3. Evanescencia: Frente a aquellos que critican la evanescencia de los soportes digitales, los defensores de la cibercultura responden que también son evanescentes los libros impresos en pasta de papel. Baste leer la Nueva historia universal de la destrucción de libros (2004), de Fernando Báez, para darse cuenta de la cantidad de libros que se han destruido a lo largo de la historia, no sólo por obra de incendios y hogueras, sino también por el mero paso del tiempo. Muchos de nuestros libros impresos se descomponen en estos mismos momentos en nuestras bibliotecas, de modo que ni son tan duraderos como sus defensores afirman, ni les es tan perjudicial el soporte digital, que puede conservarlos para que los imprimamos siempre y cuando los necesitemos.

\section{2. 2. Cualitativas}

\section{La crisis del criterio de calidad literaria no sólo no es nueva, sino que es una oportunidad:} Los partidarios de la cibercultura consideran que el criterio de valoración de la calidad literaria siempre ha estado en crisis, y que toda innovación ha sido siempre considerada como causa y efecto de una crisis de criterio. De algún modo, el debate entre anti y prodigitales no sería más que la reedición del milenario debate entre antiguos y modernos. Aun concediendo que en la actualidad la crisis del criterio es especialmente profunda, ésta no sería tanto el resultado de una mera revolución tecnológica, como del entrelazamiento de toda una serie de factores sociales -la democratización de la autoría-, económicos -la mercantilización de la literatura- o filosóficos - la crisis de la idea de verdad-. No tiene sentido, pues, caer en una especie de nihilismo tecnológico, convirtiendo la revolución digital en el chivo expiatorio de esa crisis más general, puesto que eso no sólo no va a ponerle fin, sino que puede ahondarla más todavía. La respuesta más valiente e inteligente sería tratar de conocer el nuevo paradigma, con el objetivo de construir un nuevo criterio de qué es la calidad literaria.

2. Negación de la crisis de la calidad literaria: Frente a los escépticos de la ciberliteratura, que consideran que el nuevo paradigma digital está suponiendo una degradación de la calidad literaria, sus defensores oponen los siguientes argumentos:

\section{1. Contra el argumento de la igualación cultural y cualitativa de la literatura: Para}

empezar, los defensores de la cibercultura niegan que se esté produciendo a todos los niveles una igualación cultural y cualitativa de la literatura. En primer lugar, algunos estudiosos consideran que el uso de internet no ha aumentado tanto como se esperaba la interrelación entre los diferentes grupos 
culturales, sino que ha dado lugar al refuerzo de tópicos y de fronteras. Este proceso de «ciberbalcanización», que no sería sólo el resultado de la revolución digital, sino también de la globalización, en general, habría dado lugar a la formación de grupos de afinidad estancos en internet, y sería la prueba de que no se está produciendo la tan temida igualación cultural de las culturas, en general, y de la literatura, en particular. En segundo lugar, ningún proceso de homogeneización cultural, por intenso que sea, puede durar demasiado tiempo. Todo gran imperio ha acabado deshaciéndose en una miríada de culturas. Ciertamente, el imperio romano acabó, en parte, con la heterogeneidad cultural anterior, pero no tardó muchos siglos en dar lugar a una nueva diversidad. No debemos, pues, temer a la homogeneización cultural, por la sencilla razón de que la multiplicidad de lo real es irreductible, y siempre acaba imponiéndose.

2. 2. Contra el argumento de la falta de profundidad estética: También en este punto los defensores de la cibercultura responden que todas las épocas han expresado la misma sensación de decadencia. Por otra parte, tampoco es tan reciente que la mayoría de los escritores se dispersen y prodiguen en exceso, como muestran los incontables lamentos de escritores que tuvieron que alquilar sus plumas para sobrevivir. En lo que respecta a la aceleración y a la superficialidad estética, los defensores de la cibercultura responden que ésta no es tanto el resultado de la revolución digital, como el de la aceleración de la propia sociedad. Al fin y al cabo, señala Carrière, «cuando hacemos correr un texto en nuestra pantalla, ¿acaso no encontramos algo que los lectores de volumina, de rollos, hacían antaño, es decir, la necesidad de desenrollar un texto enrollado en torno a un soporte de madera?» (Eco y Carrière, 2010: 102). Si es cierto que no existe una diferencia esencial entre el gesto de los lectores de la Biblioteca de Alejandría y el de un usuario de internet, cabe sospechar que las causas profundas de nuestros modos de leer se hallen en otro lugar. Finalmente, siempre ha existido una tensión trágica entre profundidad y ligereza, entre densidad y variedad. No es, en absoluto, deseable que ninguno de los dos polos se imponga totalmente, puesto que ambos tienen sus virtudes y sus defectos. Ciertamente, la nuestra es una época de ligereza, variedad, rapidez y superficialidad, pero eso no impide que no puedan surgir grandes obras, del mismo modo que en épocas más pesadas, como la Edad Media, también surgieron grandes obras literarias. Pero no sólo la creación, sino también la lectura puede verse beneficiada en algunos aspectos dentro del paradigma digital, pues puede hacerse más activa, curiosa, diletante y hedonista (precisamente, la etimología de dilettante es 'el que se deleita'). Tal y como señala Garberoglio, refiriéndose a la blogosfera: «este nuevo formato nos permite bucear en un mar donde también hay perlas. Y sobre todo hay un aire fresco, hay un cartel que dice «somos nuevos», hay espontaneidad en la relación con la palabra escrita. Es posible encontrar irreverencia, a veces desconocimiento de la tradición literaria, ingenuidad, pero sin duda se hace presente un espíritu de desacralización de la relación escritor- lector. La fluidez en la expresión, el lenguaje coloquial, el relato de las vivencias habituales. A través de un formato novedoso entonces, percibimos que otra de las proposiciones de Roland Barthes, aquello de leer «levantando la cabeza» y buscando así asociaciones o todo lo que pueda disparar nuestro pensamiento a partir de esa lectura, saliendo de los caminos que 
nos ofrece el autor; se plasma aquí de manera efectiva y prácticamente inherente al propio medio» (2013: 111-112).

\section{3. Contra el argumento de la crisis de la narratividad: Tampoco aceptan los defensores} de la cibercultura que la narratividad haya entrado definitivamente en crisis por culpa del nuevo paradigma digital. Para empezar, toda innovación técnica ha necesitado siempre un período de adaptación para que la sociedad aprenda a utilizarlo y a hacerle un lugar en su cosmovisión. Es normal que, mientras la literatura y el pensamiento se adaptan al nuevo paradigma cultural, cunda la sensación de que éste ha dado lugar al caos. Buñuel explica cómo, a principios del siglo XX, en los inicios del cine, existía la figura del «explicador», que aclaraba lo que estaba pasando en la pantalla, pues el nuevo lenguaje todavía era incomprensible. Seguramente nosotros nos hallamos en un momento semejante en lo que respecta a la cibernarratividad. En lo que respecta a la fragmentariedad de las obras y de las lecturas, deberíamos recordar que la lectura de los libros sagrados y de los libros clásicos era también salteada y azarosa, por no hablar de la lectura de periódicos o la lectura en F de los libros que dudamos si comprar en las librerías o consultar en las bibliotecas. Si respondemos que no se trata del mismo tipo de lectura, porque la ciberlectura no va acompañada de un comentario, glosa o desarrollo, quizás podemos pensar, con Bauman, que este tipo de cambios no viene determinado tanto por el soporte y por la técnica, como por el tipo de vida que acompaña al capitalismo tardío, que, en su tendencia a la mercantilización de la existencia, en su conjunto, ha reducido al mínimo el tiempo de la introspección, el pensamiento y la contemplación (2005: 189).

En última instancia, los defensores de la cibercultura están dispuestos a conceder que los medios técnicos pueden condicionar, si bien nunca determinar, la literatura. Decía Sartre, a mediados del siglo pasado, que el marxismo demuestra que Paul Valéry era un intelectual pequeñoburgués, pero que nunca podrá explicar por qué todos los intelectuales pequeñoburgueses no son Paul Valéry. Lo mismo dirán mañana los que estudien a los grandes escritores digitales de hoy.

\section{4. En todas las épocas ha existido una cierta mercantilización de la obra y el autor:} Los defensores de la cibercultura tampoco aceptan que ésta sea reponsable del proceso de mercantilización posindustrial de la literatura. Para empezar, en todas las épocas ha existido una cierta mercantilización de las obras y las autores. Recuérdese por ejemplo, «El rey burgués», de Rubén Darío, o la escritura prácticamente industrial de autores como Balzac, Zola o Dickens, por no hablar de los escritores periodistas o de las restricciones impuestas a escritores y artistas, en general, por el mecenazgo.

3. Contra el argumento de la crisis del aura o valor cultual del libro: Los defensores de la cibercultura no consideran que la crisis del aura o valor cultural del libro sea una tragedia. Lo que está sucediendo, simplemente, es una «ampliación del campo de las legitimidades culturales» (García Canclini, 2015: 13). Los filósofos cínicos y los primeros monjes franciscanos rechazaban la posesión de libros, por considerarla expresión de avaricia, lujo, orgullo y fatuidad. Numerosos escritores románticos y filósofos vitalistas han cargado contra los libros, por verlos como una tentación a retardar 
nuestra cita con la virtud y la vida. Por otra parte, el «Culto a los libros», del que hablaba Borges, seguirá existiendo para una parte de la sociedad, tan exigua como en cualquier otra época. En última instancia, tal y como afirma García Canclini, en El mundo entero como lugar extraño (2015a), no deberíamos sentir tanta aprensión por toda una serie de transformaciones que nacieron antes de las computadoras personales, internet y las redes sociales; al fin y al cabo, «los relatos no lineales, la interactividad con el lector, la subversión de la metafísica que imaginaba la lengua como representación del mundo. Mallarmé, Perec, Calvino y Cortázar ensayaron con lápices o en máquinas de escribir hipertextos y reescrituras. [...] todos estos textos fueron escritos a mano» (2015a: 81).

4. Contra el argumento de la crisis del pensamiento: Los partidarios de la cibercultura también niegan que ésta haya provocado una cierta degradación del pensamiento. Aceptan que la neuroplasticidad del cerebro está suponiendo una cierta interiorización cognitiva de la cibercultura, por lo menos en lo que respecta a cuatro funciones básicas del pensamiento, como son la abstracción, la introspección, la contemplación y la memoria. Sin embargo, rechazan que dichos cambios sean inéditos y, aun más, que sean negativos.

En lo que respecta a la crisis de la abstracción, por ejemplo, causada supuestamente por la aceleración del pensamiento y el impacto del lenguaje visual, puede responderse que dicha aceleración es anterior e independiente de la revolución digital y que existen culturas con escrituras ideográficas, como los kanjis orientales, no tan diferentes de los emoticonos, con una filosofía que ha llegado a altas cotas de abstracción. Por otra parte, ninguna época histórica ha podido verse a sí misma con la distancia suficiente. Hegel utilizaba la imagen de la lechuza de Minerva, que alzaba el vuelo al atardecer, precisamente para indicar que la comprensión del propio momento histórico sólo empieza a ser posible cuando éste está declinando.

En lo que respecta a la crisis de la introspección y la contemplación, los defensores de la cibercultura insistirán en que no es tanto un efecto de la revolución digital como de un cambio cultural mucho más amplio. Ciertamente, en el capitalismo tardío, la tendencia mercantilizadora del capital ha acabado afectando a toda la realidad, tanto extensiva (todos los países, todas las realidades físicas, todos los tiempos), como intensivamente (las ideas, la intimidad, la rebelión misma puede comercializarse). Este hecho ha supuesto una grave erosión de la introspección (que nos libera de la dependencia de la mirada de los otros, motor fundamental de las industrias del aspecto físico o de las redes sociales) y la contemplación (que consiste, ya desde Aristóteles, en una desconexión de la mirada utilitaria y, por lo tanto, comercial), por haber pasado a ser vistas o sentidas como tiempos no productivos y como obstáculos para la comercialización de la inmidad y el ocio.

En lo que respecta a la crisis de la memoria, los partidarios de la cibercultura afirman que ésta ya se vivió en el mismo momento en que apareció la escritura. Así lo consigna Platón, en el Fedro, al expresar, en boca de Sócrates, sus temores de que la escritura pueda acabar con la memoria, la meditación y la práctica. Tampoco es casual que nunca se publicasen tantos libros de mnemotecnia como durante las primeras décadas de existencia de la imprenta. Ciertamente, nuestro uso tradicional 
de la memoria está cambiando y, mientras no se establece una nueva cultura memorística, pueden producirse numerosas disfunciones y carencias. Sin embargo, la memoria es una realidad inserta en la historia que no puede sino cambiar. Nuestra función no es, pues, lamentarnos de que cambie, sino tratar de darle la mejor forma posible a esos cambios.

5. Contra el argumento de la decadencia ética y política: Los partidarios de la cibercultura también se oponen a aquellos argumentos que afirman que la degradación de la calidad de la literatura y el pensamiento está teniendo graves consecuencias éticas y políticas, que en muchos casos supondrían un grave peligro para la supervivencia de la democracia, cuando no de la especie humana.

5. 1. Contra el argumento de la crisis de la democracia: Aunque los defensores de la cibercultura no niegan que existe una conexión estrecha entre formación, lectura y democracia, se resisten a aceptar que la cibercultura haya supuesto una erosión significativa de dichas relaciones. Aun concediendo que se esté produciendo dicha erosión, cabe pensar que, con otras políticas culturales y económicas, la cibercultura podría convertirse más en una ayuda que en un problema para la formación de los ciudadanos. Lo cierto es que el uso de las redes sociales ha sido visto por muchos teóricos de la política como una oportunidad para renovar la democracia, haciéndola más directa y participativa. Es indiscutible su función política en el seno de las primaveras árabes y de los movimientos indignados, como, desgraciadamente, en el de los grupos de ultraderecha o en el del autodenominado Estado Islámico.

5. 2. Contra el argumento de la crisis de la empatía: Los partidarios de la cibercultura tampoco aceptan que su advenimiento haya supuesto una erosión de nuestras capacidades empáticas. Más bien al contrario, el universo de discurso ético se ha visto aumentado hasta coincidir con la totalidad del planeta. Ciertamente, desastres climáticos, hambrunas o guerras, que antes podían dejarnos intocados, ya fuese porque los sintiésemos demasiado lejanos o, simplemente, porque ignorásemos su existencia, ahora se nos presentan como elementos omnipresentes y cercanos. Asimismo, nuestro sentimiento de responsabilidad se ha ampliado hasta exceder los límites de nuestras comunidades regionales o nacionales, hasta hacernos sentir responsables de cosas que pasan a miles de kilómetros de nuestro radio directo de acción. Comprar ropa que ha podido ser fabricada por niños en países subdesarrollados, por ejemplo, es un gesto que angustia cada vez a más gente. Por otra parte, no es extraño que muchos de nosotros tratemos de mirar, de vez en cuando, hacia otro lado cuando el peso de las noticias internacionales nos abruma, pues los sentimientos de empatía, responsabilidad y culpa tienen también sus límites. Desde esta perspectiva, no podemos decir que la empatía esté en crisis, sino que se está reformulando.

\section{3. Contra el argumento de la cibermanipulación de la información: En lo que respecta} a la idea de que el nuevo paradigma digital está permitiendo que se creen redes masivas de espionaje y de control, los defensores de la cibercultura responden que todavía debe generalizarse una cultura de la intimidad, que gestione de forma más racional y prudente la autoexposición. Asimismo, al mismo tiempo que se formaban esas redes de espionaje y de control, se formaban también redes de bloqueo, 
como sería el caso de algunos hackers de tendencia libertaria, o campañas de denuncia, como fue el caso de Wikileaks o de Edward Snowden.

5. 4. Contra el argumento del imperativo de la conexión y la disponibilidad: En lo que respecta a la cuestión de la autoexposición compulsiva de la propia intimidad, conocida también como «extimidad», los defensores de la cibercultura afirman que ésta no es resultado exclusivo de la revolución digital. Según afirma Zygmunt Bauman, en uno de los libros más interesantes acerca de la disolución de la identidad en el siglo XXI, intitulado Identidad, tanto la extimidad como la progresiva dependencia de las redes sociales se explica «porque echamos dolorosamente de menos las redes de seguridad que los auténticos canales de familiares, amigos y compañeros con el mismo destino solían proporcionarnos» (2005: 197). No debemos, pues, pensar que es la tecnología la que ha transformado nuestro modo de ser en común, sino que, antes bien, es la licuefacción del tejido social lo que nos ha llevado a buscar en la tecnología un sustituto, siempre insatisfactorio (189). En última instancia, los partidarios de la cibercultura consideran que basta con una nueva cultura de gestión de la intimidad para solucionar un problema que, en todo caso, no es motivo suficiente para renunciar a todas las ventajas que encierra el nuevo paradigma digital.

\section{Conclusiones}

Toda revolución tecnológica, en particular, y toda época de crisis, en general, suele despertar una gran efervescencia mitológica. No es extraño que el advenimiento del paradigma digital haya dado lugar a una «tecnomitología», constituida por toda una serie de ideas, prejuicios, mitemas y ocurrencias, que van desde «la credulidad ingenua al cinismo cáustico» (López-Pellisa, 2015: 14). Según estudió Raoul Girardet, en Mitos y mitologías políticas (1986), este tipo de actividad imaginaria suele organizarse alrededor de cuatro constelaciones mitológicas: el mito de la edad de oro, que tiende a idealizar lo que había antes y prometerse su regreso en un futuro más o menos cercano; el mito de la conspiración, que tiende a creer que los desórdenes o inconvenientes causados por la crisis han sido buscados por alguna instancia oculta, sedienta de poder; el mito del mesías o persona providencial, que suele verse ligado a algún tipo de espera apocalíptica; y el mito de la unidad, que afirma la existencia de una realidad esencial que debe mantenerse y defenderse ante la crisis. Como era de esperar, el advenimiento del paradigma digital ha provocado un conjunto de reacciones semejantes:

1. Mito de la edad de oro: Entre los detractores de la cibercultura, existe cierta tendencia a idealizar la vida del hombre antes de la llegada de la revolución industrial, en general, y de la revolución digital, en particular. Se considera que el mundo digital ha distorsionado las relaciones, antes naturales, del hombre con la realidad y con los demás hombres. Este malestar lleva a algunos a entregarse a fantasías escapatorias de corte apocalíptico, como que un gran apagón, virus informático o colapso energético podría devolvernos a un estadio semejante al anterior. Del otro lado, los entusiastas de lo digital anuncian la llegada de un mundo maravilloso, en el que la técnica resolverá todas las contradicciones de nuestra existencia. 
2. Mito de la conspiración: Los críticos de la cibercultura suelen considerar que ésta ha venido a completar el proceso, más o menos automático e inconsciente, de control y autocontrol burocrático, al que Max Weber ya se refirió, en el siglo XIX, con el término «jaula de hierro» y que Jeremy Bentham anunció con su invención del panóptico. Desde este punto de vista, el nuevo paradigma digital no habría venido a liberarnos, sino a aumentar las herramientas de los poderes fácticos para el mantenimiento del sistema (cf. Niklas Luhman). Los entusiastas de la cibercultura, en cambio, consideran que el mundo de lo digital ha supuesto una auténtica revolución política, por cuanto ha aumentado la capacidad de representación, diálogo y participación políticas. Muchos políticos, reformistas o revolucionarios, estatalistas o libertarios, cifran sus esperanzas de cambio en el uso de internet.

3. Mito del hombre providencial: Los detractores de la cibercultura temen que las potencialidades técnicas del nuevo paradigma puedan ser concentradas en manos de una aristocracia, partido o individuo que pudiese realizar un mal uso de ellas. Serían paradigma de este tipo de usos maléficos las campañas de espionaje masivo, así como la propaganda y captación de grupos terroristas. A este tipo de figuras maléficas, de corte mitológico, se le opondrían otras figuras, rodeadas de un aura mesiánica, como, por ejemplo, el fundador de Wikileaks, Julian Assange; el extrabajador de la CIA que hizo públicos documentos de alto secreto de la NSA estadounidense, Edward Snowden; o el grupo de hacktivista, o hackers politizados, Anonymous.

4. Mito de la unidad: El orden es el mantenimiento invisible de una unidad, que se revela en peligro cuando empieza a imponerse el desorden. Mil soldados huyendo en desbanda no forman un ejército. Por esta razón, el desorden provocado por cualquier tipo de crisis, y en este caso por la revolución digital (a pesar de no ser más que un epifenómeno de la crisis económica, política, social y cultural, que llamamos globalización), despierta el fantasma de la unidad amenazada. Dicho fantasma puede cubrirse con muchas sábanas diferentes: la de la nación amenazada (como dijimos la red ha contribuido, paradójicamente, a una ciberbalcanización), la de la religión asediada (existe una gran batalla simbólica en la red entre el cristianismo y el islamismo), la de la clase social en lucha (el ciberactivismo político ha vuelto a poner en marcha el imaginario de la lucha de clases y la idea de que la identidad social debe prevalecer sobre la nacional o la religiosa) o la de la unidad del ser humano (que es vista como el único modo de oponerse a problemas globales que la amenazan, y a la vez la han dotado de conciencia: ecología, terrorismo global, mafias y desfase entre la desregularización económica y la incapacidad de la política para trascender el marco nacional).

Todo esto nos hace sospechar que tienen razón el antropólogo como Lévi-Strauss y el epistemólogo como Paul Feyerabend, cuando afirman que nuestras relaciones con la técnica más avanzada no se diferencian en exceso de las relaciones que los llamados «primitivos» o «salvajes» mantenían con el mundo de la magia. ¿Qué postura debemos adoptar, entonces? Para empezar, deberíamos rechazar las visiones reduccionistas y maniqueas que oponen de forma radical la cultura 
digital y la cultura letrada, por la sencilla razón de que «también la escritura es una tecnología que fue inventada hace algunos siglos y que, como tal, en su momento se impuso sobre la oralidad» (Garberoglio, 2013: 103).

Por su parte, en su libro, ya clásico, Apocalípticos e integrados (1977 [1965]), dedicado al análisis de la «cultura de masas»o «cultura mediática», Umberto Eco nos exhorta a distanciarnos de los juicios extremos, propios de los dos tipos de intelectuales a los que hace referencia el título de su libro. De un lado, el apocalíptico considera que «la cultura es un hecho aristocrático», mientras que «la cultura de masas es la anticultura», que anuncia «una caída irrecuperable» (12). Con todo, entre los apocalípticos se produce la paradoja de que sus jeremiadas representan «el producto más sofisticado que se ofrece al consumo de masas» (13). Ya en los años sesenta, Pierre Bourdieu y JeanClaude Passeron hablaron de «la profecía massmediática», afirmando que ésta duda «entre la nostalgia de un verde paraíso de civilizaciones infantiles y la esperanza desesperada de un mañana apocalíptico» (cit. en Eco, 1977: 19). En el otro extremo, el integrado es «optimista», pues considera que la cultura de masas es «una época de ampliación del campo cultural», y no se plantea las características de esta nueva cultura, porque «mientras los apocalípticos sobreviven precisamente elaborando teorías sobre la decadencia, los integrados raramente teorizan, sino que prefieren actuar, producir, emitir, cotidianamente sus mensajes a todos los niveles» (13).

Umberto Eco no duda en criticar ambos extremos, que verá encarnados en las obras La perdida del centro (1948), de Sedlmayr y Entendiendo los media (1964), de McLuhan. Según Eco, anque ambos autores ven el mundo desde ángulos diametralmente opuestos, «se sirven de los mismos argumentos para apoyar sus tesis. Mejor dicho: invocan los mismos hechos, pero uno los considera como símbolos y el otro como síntomas, uno los carga de tintes sombríos y plañideros, mientras el otro los juzga con jovial optimismo» (1977: 385). Debemos resistirnos, pues, a los cantos de sirena de la simplicidad -utópica o apocalíptica- y optar por una vía media, tanto en lo que respecta al diagnóstico, como en lo que respecta al tratamiento. Debemos aceptar que el universo de las comunicaciones de masas y de la cibercultura es nuestro universo, para luego asumir, con Marx, que «si el hombre es formado por las circunstancias, las circunstancias deben volverse humanas» (cit. en Eco, 24). Sólo de este modo podremos enfocar de forma racional y productiva la época que nos ha tocado vivir, lograno «no un hombre liberado de la máquina», mas sí un hombre «libre en relación a la máquina» (Eco, 1977: 21). 


\section{Bibliografía}

Abuín GonZÁlez, A. (2008): «Teatro y nuevas tecnologías: conceptos básicos», Signa. Revista de la Asociación Española de Semiótica, 17, pp. 29-56.

Abuín González, A. - Vilariño Picos, M. T. eds. (2006): Teoría del hipertexto: La literatura en la era electrónica. Madrid, Arco/Libros.

ALAYÓN GÓMEZ, Jerónimo (2009): «Perspectivas y problemas de la narrativa hipertextual», Alicante,

Biblioteca Virtual Cervantes; en http://www.cervantesvirtual.com/nd/ark:/59851/bmc8g936 (última consulta, 1-9-2017).

ANIS, Jacques (1998): Texte et ordinateur: l'écriture réinventée. Paris-Bruxelles, De Boeck.

BÁEZ, Fernando (2004): Nueva historia universal de la destrucción de libros. Barcelona, Destino.

BARAHOnA, Dorelia - Bertsch, Floria - Bonilla, Janina - MurIllo, Catalina - ORdóÑEZ, Jaime -

VAldelomar, Víctor - Viñuales, Pedro Pablo (2007): Milagros sueltos. Alicante, Biblioteca

Cervantes Virtual; en http://www.cervantesvirtual.com/bib/portal/literaturaelectronica/novela

150b.html?fqstr=1\&qPagina=0\&qImagen=1 (última consulta, 1-9-2017).

BARCELÓ GARCÍA, Miquel (2005): La inteligencia artificial. Barcelona, UOC.

BARTHES, Roland (2010): La cámara lúcida. Barcelona, Paidós.

BAUDRILLARD, Jean (1983): Las estrategias fatales. Barcelona, Anagrama.

— (2001): Cultura y simulacro. Barcelona, Kairós.

BAUMAN, Zygmunt (2005): Identidad. Buenos Aires, Losada.

BAYARD, Pierre (2007): Cómo hablar de los libros que no se han leído. Barcelona, Anagrama, 2. ${ }^{\text {ed., }}$ 2011.

BENJAMIN, Walter (1936): La obra de arte en la época de su reproductibilidad mecánica. Madrid, Casimiro, 2010.

Berg, Maggie - SEEBER, Barbara K. (2016): The Slow Professor: Challenging the Culture of Speed in the Academy. Toronto, University of Toronto Press.

Bergamín, José (1933): La decadencia del analfabetismo. La importancia del demonio. Madrid, Siruela, 2006.

BiBLIOTECA DE LITERATURA DIGITAL: LiTERATURA DigITAL EN ESPAÑOL (2012-2015): Biblioteca de literatura digital: Literatura Digital en Español. Madrid, Universidad Compluntense; en http://repositorios.fdi.ucm.es/CIBERIA (última consulta, 1-9-2017).

BLOOM, Harold (1994): El canon occidental. Barcelona, Anagrama, 1995.

BRIN, David (1998): The transparent Society. Nueva York, Penguin Books.

BusH, Vannevar (1945): «As we may think», The Atlantic Monthly, 176/1, pp. 101-108.

CADOZ, Claude (1995): Las realidades virtuales. Madrid, Debate Dominós.

CARR, Nicholas (2011): Superficiales. ¿Qué está haciendo Internet con nuestras mentes? Madrid, Taurus.

CARriÈre, Jean-Claude - Eco, Umberto (2010): Nadie acabará con los libros. Barcelona, Lumen.

CARrión, Jordi (2015): «Querido (y agónico) diario», El País, 1 de noviembre. 
CASA JANICES, Ana (2014): Fabulaciones del yo. Nuevas aproximaciones críticas a la autoficción. Frankfurt, Iberoamericana-Vervuert.

CASACUBerTa, David (2003): Creación colectiva. En internet el creador es el público. Barcelona, Gedisa.

CASCIARI, Hernán (2005): Más respeto que soy tu madre. Barcelona, Plaza \& Janés. (2006): «La ficción on line. Un espectáculo en directo», en La blogosfera hispana: pioneros de la comunicación digital. Madrid, Omán Impresores/France Telecom, pp. 171-179.

CASEY, Larijani L. (1994): Realidad virtual. Madrid, McGraw-Hill.

CASSANY, Daniel (2006): Tras las líneas. Barcelona, Anagrama.

CASTANY PRADO, Bernat (2007): Literatura posnacional. Murcia, Editum.

Chartier, Roger - Rodríguez de las Heras, Antonio (2001): «El futuro del libro y el libro del futuro», Litterae: cuadernos sobre cultura escrita, 1, pp. 11-42.

CHECA, Edith (1995): Como el cielo los ojos, en http://www.badosa.com/bin/obra.pl?id=n052 (última consulta, 1-9-2017).

ChiAPPE, D. ed. (2005): La huella del cosmos. Biblioteca Cervantes Virtual, en http://www.cervantes virtual.com/obra/la-huella-de-cosmos/ (última consulta, 1-9-2017).

CICCORICCO, David (2007): Reading Network Fiction. Tuscaloosa, University of Alabama Press.

CoDINA, Lluis (2000): El libro digital y la WWW. Madrid, Tauro Producciones.

COMER KIDD, David - CASTANO, Emanuele (2013): «Reading Literary Fiction Improves Theory of Mind», Science, 342, pp. 377-380.

CORRAL CAÑAS, Celia (2012): «Ciberpoetas y ciberlectores: arquitectos del ciberespacio», Caracteres. Estudios culturales y críticos de la esfera digital, 1/1, pp. 11-17; en http://revistacaracteres.net/ revista/vol1n1mayo2012/ciberpoetasgygciberlectoresgarquitectosgdelgciberespacio (última consulta 1-9-2017).

Covadonga LóPez, Alonso - SeRÉ, A. eds. (2003): Nuevos géneros discursivos: los textos electrónicos. Madrid, Biblioteca Nueva.

CRARY, Jonathan (2015): «La vida sin pausa», El País, 24 de mayo de 2015; en http://cultura.elpais. com/cultura/2015/05/20/actualidad/1432123650_805121.html (última consulta, 1-9-2017).

CUESTA, Mery (2003): «El nacimiento del ciberensayo», Lateral: Revista de Cultura, 99, p. 37.

DACHS, Ramon (2005): Intermínimos de navegación poética, Casatomada, 5, html; en http://web. archive.org/web/20080819215141/http://www.uoc.edu/in3/hermeneia/interminims/pcsearcc.htm (última consulta, 1-9-2017).

DíEZ, Juan José (2006): Don Juan en la frontera del espíritu. Biblioteca Cervantes virtual; en http://www.cervantesvirtual.com/bib/portal/litElec/webnovelaJJDiez/ (última consulta, 1-9-2017). (2009): «Presentación», en Literatura electrónica hispánica. Alicante, Biblioteca Virtual Cervantes; en http://www.cervantesvirtual.com/bib/portal/literaturaelectronica/ (última consulta, 1-9-2017). 
DiXON, Steve (2007): Digital Performance. A History of New Media in Theater, Dance, Performance Art, and Installation. Cambridge, The MIT Press.

ECO, Umberto (1965): Apocalípticos e integrados. Barcelona, Lumen, 1977.

EL REGRESO DE CECILIO (s. f.): El regreso de Cecilio. Wikinovela, en http://fiction.wikia.com/wiki/El

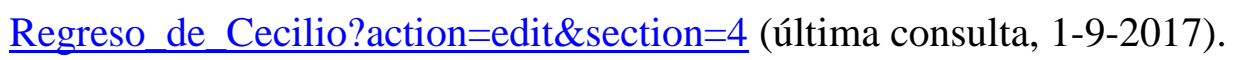

EsCAJA, Tina (2000): Velo City. Html; en http://www.uvm.edu/ tescaja/poemas/hyperpoemas/ velocity.php (última consulta, 1-9-2017).

EsCALONILlA, Benjamín (2000): Sinferidad. Html; en http://www.erres.com/abran-esa-malditapuerta/sinferidad/ (última consulta, 1-9-2017).

ESCANDELl, Daniel (2014): Escrituras para el siglo XXI. Literatura y blogosfera. Madrid, Iberoamericana.

FERrÉ, Juan Francisco - ORTEGA, Julio, eds. (2007): Mutantes. Narrativa española de última generación. Córdoba, Berenice.

FUnDACIÓN TELEFÓNICA (2012): La Sociedad de la Información 2011. Barcelona, Ariel.

GAMERro, Carlos (2003): Harold Bloom y el canon literario. Madrid, Campo de ideas.

GARberoglio, María de la Paz (2013): «Literatura y nuevas tecnologías. Cambios en las nociones de lectura y escritura a partir de los weblogs», Cuadernos del Centro de Estudios de Diseño y Comunicación, 45, pp. 103-114.

GARCÍA, Toni (2013): «Ha nacido la tuiteratura», El País, 12 de mayo; en http://cultura.elpais.com/ cultura/2013/05/11/actualidad/1368297293 409130.html (última consulta, 1-9-2017).

GARCÍA-CANCLINI, Néstor (2015a): El mundo entero como lugar extraño. Barcelona, Gedisa. (2015b): Hacia una antropología de los lectores. Madrid, Fundación Telefónica-Ariel.

Gendolla, P. - JÖRGEN, S., eds. (2010): Beyond the Screen. Transformations of Literary Structures, Interfaces and Genres, Trasncript, Bielefeld (Alemania).

GIBSON, William (2007): Neuromante. Barcelona, Minotauro.

GIRARDET, Raoul (1986): Mythes et mythologies politiques. París, Seuil.

Gómez TRUEBA, Teresa (2002): «Creación literaria en la Red: de la narrativa posmoderna a la

hiperficción», Espéculo. Revista de Estudios Literarios, 22, html; en http://www.ucm.es/info/ especulo/numero22/cre_red.html (última consulta, 1-9-2017).

GonZÁlez García, María (2009): Educar con el Quijote. Del canon al hipertexto. Murcia, Editum.

GUERRIERI, Marcelo (2006): Detective bonaerense. Biblioteca Cervantes Virtual; en http://www. cervantesvirtual.com/obra/detective-bonaerense/ (última consulta, 1-9-2017).

GutiÉRrez, J. B. (1998): Condiciones extremas. Html; en http://www.literatronica.com/src/ Nuntius.aspx? ?ng=HISPANIA\&nuntius=OPUS_ABOUT_1\&opus=1 (última consulta, 1-92017).

HAN, Byung-Chul (2012): La sociedad de la transparencia. Barcelona, Herder.

HANDY, Charles (2001): The Elephant and the Flea. Hutchison, Random House. 
HARgREAVES, Andy (2003): Teaching in the Knowledge Society: Education in the Age of Insecurity. Maidenhead, Open University Press.

ILlouz, Eva (2007): Intimidades congeladas. Madrid, Katz.

INNERARITY, Daniel (2015): «Libertad como desconexión», El País, 21 de mayo; en http://elpais.com/ elpais/2015/05/21/opinion/1432228354_208918.html (última consulta, 1-9-2017).

IWASAKI, Fernando (2009): España, aparta de mí estos premios. Madrid, Páginas de Espuma.

KAC, Eduardo (1983-1993): Holopoems. Html; en http://www.ekac.org/allholopoems.html (última consulta, 1-9-2017).

L'ECUYER, Catherine (2015): Educar en la realidad. Barcelona, Plataforma.

LamarCa Lapuente, María Jesús (2005): Hipertexto: el nuevo concepto de documento en la cultura de la imagen. Madrid, Universidad Complutense de Madrid; en http://www.hipertexto.info/ (última consulta, 1-9-2017).

LANDOW, George (1991): Hypermedia and Literary Studies. Cambridge, MIT. (2006): Hipertexto 3.0. Barcelona, Paidós, 2008.

LARSEN, Deena (1999): «About Stained Word Window», Word Circuits; en http://www.wordcircuits. com/gallery/stained/index.html (última consulta, 1-9-2017).

LATOUCHE, Serge (2009): Decrecimiento y posdesarrollo: el pensamiento creativo contra la economía del absurdo. Barcelona, Icaria.

- (2011): La hora del decrecimiento. Barcelona, Octaedro.

LEJEUnE, Philippe (1994): El pacto autobiográfico y otros estudios. Madrid, Megazul-Endymion.

LÉvy, Pierre (1998): ¿Qué es lo virtual? Barcelona, Paidós.

LIPOVETSKY, Gilles - CHARLES, Sébastien (2004): Los tiempos hipermodernos. Barcelona, Anagrama, 2006.

LITERATURA ELECTRÓNICA HISPÁNICA (s. f.): Literatura electrónica hispánica, Biblioteca Cervantes Virtual, Universidad de Alicante; en http://www.cervantesvirtual.com/bib/portal/literatura electronica/ (última consulta, 1-9-2017).

LiteratuRAS ESPAÑOLAS Y EUROPEAS DEL TEXTO AL HiPERTEXTO (s. f.): Literaturas Españolas y Europeas del Texto al Hipertexto, Universidad Complutense de Madrid; en https://www.ucm.es/ leethi/que (última consulta, 1-9-2017).

LÓPEZ-PELlisA, Teresa (2013a): «La pantalla en escena: ¿Es teatro el ciberteatro?», Revista Letral, 11, pp. 24-39.

(2013b): «Teatro de robots: actores mecánicos y digitales con alma de software», en José ROMERA CASTILLO, ed., Teatro e Internet en la primera década del siglo XXI. Madrid, Verbum, pp. 219-234.

(2015): Patologías de la realidad virtual. Cibercultura y ciencia ficción. México, Fondo de Cultura Económica.

MANGEN, Anne (2013): «Putting the body back into reading», en Paedagogisk Neurovidenskab, Aarhus, DPU, Aarhus Universitet, pp. 11-33. 
(2014): Reading on paper and screens: Empirical research, conferencia dictada en la Bournemouth University, Gran Bretaña, 19 de junio.

MANGuel, Alberto (1996): Historia de la lectura. Madrid, Alianza, 2013.

MARChamalo, Jesús (2010): Tocar los libros. Madrid, Fórcola.

MAYOS, Gonzalo (2001): «Presentación», en Friedrich Nietzsche, El nihilismo en los escritos póstumos. Barcelona, Península, pp. 5-35.

MENDOZA, Eduardo (2006): «Un informe sobre la lectura», Revista de libros, 1 de septiembre; en http://www.revistadelibros.com/articulos/historia-de-la-lectura\#note6 (última consulta, 1-92017).

Monterroso, Augusto (1995): «Cómo me deshice de quinientos libros», en Tríptico: Movimiento perpetuo. La palabra mágica. La letra E. México, Fondo de Cultura Económica, pp. 85-89.

MuRRAY, Janet (1999): Hamlet en la holocubierta: el futuro de la narrativa en el ciberespacio. Barcelona, Paidós.

NAUDÉ, Gabriel (2008): Recomendaciones para formar una biblioteca. Oviedo, KRK.

NIELSEN, Jakob (2006): «F-Shaped Pattern For Reading Web Content», Nielsen Norman Group; en https://www.nngroup.com/articles/f-shaped-pattern-reading-web-content/ (última consulta, 1-92017).

ORIHUELA, Luis Orihuela (2006): La revolución de los blogs. Madrid, La esfera de los libros.

PÉREZ-LANZAC, Carmen - RinCón, Reyes (2009): «Tu “extimidad” contra mi intmidad», El País, 24 de marzo; en http://elpais.com/diario/2009/03/24/sociedad/1237849201_850215.html (última consulta, 1-9-2017).

PRON, Patricio (2016): «La parte real / Jugando a escribir una novela (en lugar de escribirla)», Prodavinci, 11 de febrero; en http://prodavinci.com/blogs/la-parte-real-jugando-a-escribir-unanovela-en-lugar-de-escribirla-por-patricio-pron/ (última consulta, 1-9-2017).

- (2016): «Marca un poema o tuitéalo», El País, 26 de marzo; en http://cultura.elpais.com/cultura/ 2016/03/22/actualidad/1458657835_951609.html (última consulta, 1-9-2017).

PUZZLING Web HABITS ACROSS THE GlOBE (2008): «Puzzling Web Habits across the Globe», Blog ClickTale, 31 de julio; en https://www.clicktale.com/academy/blog/puzzling-web-habits-acrossthe-globe-part-1/ (última consulta, 1-9-2017).

REMíREZ, Félix (2007): Una contemporánea historia de Caldesa. Biblioteca Cervantes Virtual; en http://www.cervantesvirtual.com/bib/portal/litElec/Caldesa_Felix_Remirez/ (última consulta, 19-2017).

REVEL, Jean-François (1988): El conocimiento inútil. Madrid, Austral, 2007.

RODRíGUEZ DE LAS HERAS, Antonio (2004): «Necesidades de formación y experimentación. El hipertexto informativo», Telos: Cuadernos de comunicación e innovación, 59, pp. 75-86.

RoDríGUEZ RuIZ, Jaime Alejandro (2006): El relato digital. Hacia un nuevo arte narrativo. Bogotá, Libros de Arena. 
ROMERo LÓPEZ, Dolores (2011): «La literatura digital en español: estado de la cuestión», Texto Digital, 7/1, pp. 38-66.

RosA, Hartmut (2015): Social acceleration: a new theory of modernity. New York, Columbia University Press.

RuIz RoBles, Ángela (2016): «Google rinde homenaje a la precursora del 'eBook'», El País, 29 de marzo; en http://cultura.elpais.com/cultura/2016/03/28/actualidad/1459145834_002175.html (última consulta, 1-9-2017).

SAID, Edward W. (2007): Orientalismo. Barcelona, DeBolsillo.

SARTORI, Giovanni (1997): Homo videns. La sociedad teledigirida. Madrid, Taurus, 2002.

SCHÄFER, J. - SIMANOWSKI, R., eds. (2010): Reading Moving Letters. Digital Literature in Research and Teaching: A Handbook. Bielefeld, Transcript.

SENNETT, Richard (2011): El declive del hombre público. Barcelona, Anagrama.

SiBILIA, Paula (2008): La intimidad como espectáculo. México, Fondo de Cultura Económica.

Stoll, Clifford (1995): Silicon Snakeoil. Nueva York, Doubleday.

TALENS, Jenaro (1994): Escritura contra simulacro. El lugar de la literatura en la era de la electrónica. Valencia, Universitat de València.

Tisselli, Eugenio (2006): Poesía asistida por computadora; en http://www.motorhueso.net/pac/ (última consulta, 1-9-2017).

TORTOSA, Virgilio, ed. (2008): Escrituras digitales. Tecnologías de la creación en la era virtual. Alicante, Universidad de Alicante.

Toulmin, Stephen (2001): Cosmópolis. El trasfondo de la modernidad. Barcelona, Península.

URIBE, Ana María (1997-2003): Tipoemas y anipoemas. Html; en http://amuribe.tripod.com/ (última consulta, 1-9-2017).

VALENCIA, Leonardo (2006): El libro flotante de Caytran Dölphin. Madrid, Funambulista. 